\title{
Mesoscale variability in the Arabian Sea from HYCOM model results and observations: impact on the Persian Gulf Water path
}

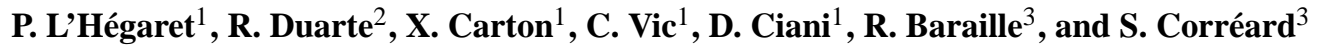 \\ ${ }^{1}$ LPO UMR 6525, UNO/UEB - CNRS-IFREMER-IRD, UFR Sciences et Techniques/IUEM, Brest, France \\ ${ }^{2}$ ACTIMAR, Brest, France \\ ${ }^{3}$ SHOM, Toulouse, France
}

Correspondence to: P. L’Hégaret (pierre.lhegaret@univ-brest.fr) and X. Carton (xcarton@univ-brest.fr)

Received: 5 January 2015 - Published in Ocean Sci. Discuss.: 12 March 2015

Revised: 7 August 2015 - Accepted: 24 August 2015 - Published: 2 September 2015

\begin{abstract}
The Arabian Sea and Sea of Oman circulation and water masses, subject to monsoon forcing, reveal a strong seasonal variability and intense mesoscale features. We describe and analyze this variability and these features, using both meteorological data (from ECMWF reanalyses), in situ observations (from the ARGO float program and the GDEM - Generalized Digital Environmental mode - climatology), satellite altimetry (from AVISO) and a regional simulation with a primitive equation model (HYCOM - the Hybrid Coordinate Ocean Model). The model and observations display comparable variability, and the model is then used to analyze the three-dimensional structure of eddies and water masses with higher temporal and spatial resolutions than the available observations. The mesoscale features are highly seasonal, with the formation of coastal currents, destabilizing into eddies, or the radiation of Rossby waves from the Indian coast. The mesoscale eddies have a deep dynamical influence and strongly drive the water masses at depth. In particular, in the Sea of Oman, the Persian Gulf Water presents several offshore ejection sites and a complex recirculation, depending on the mesoscale eddies. The associated mechanisms range from coastal ejection via dipoles, alongshore pulses due to a cyclonic eddy, to the formation of lee eddies downstream of Ra's Al Hamra. This water mass is also captured inside the eddies via several mechanisms, keeping high thermohaline characteristics in the Arabian Sea. The variations of the outflow characteristics near the Strait of Hormuz are compared with variations downstream.
\end{abstract}

\section{Introduction}

The circulation and water masses in the northern Arabian Sea and the Sea, or Gulf, of Oman are investigated here using a numerical ocean model at mesoscale resolution and in situ and remote sensing data. The focus lies here on the seasonal structure and variability of intense mesoscale features and on their impact on the outflow of Persian Gulf Water (hereafter PGW).

In the Indian Ocean, atmospheric and oceanic processes strongly reflect the monsoonal cycle. This study focuses on the northwestern part of this ocean, the Arabian Sea, north of $18^{\circ} \mathrm{N}$. Figure 1 presents the basins of interest and geographical locations. In the Arabian Sea, the winter monsoon lasts from November to February, with steady northeasterly winds up to $10 \mathrm{~m} \mathrm{~s}^{-1}$ on average. The winds reverse in summer to blow from the southwest from June to September, with a stronger intensity, up to $14 \mathrm{~m} \mathrm{~s}^{-1}$ on average. The monsoons are interleaved by short transition periods in spring and fall when winds are weaker and variable in direction (see Defant, 1961).

These steady winds have several impacts on the ocean (see Schott and McCreary Jr., 2001). They induce an Ekman transport during the monsoon seasons, chasing away the water from the coasts in summer and pushing towards them towards the coast in winter. Consequently this creates upwellings and downwellings along the coasts (see Shi et al., 2000). The most noticeable upwellings occur near the Somalia and Oman coasts, with vertical velocities up to $3 \times 10^{-2}$ 


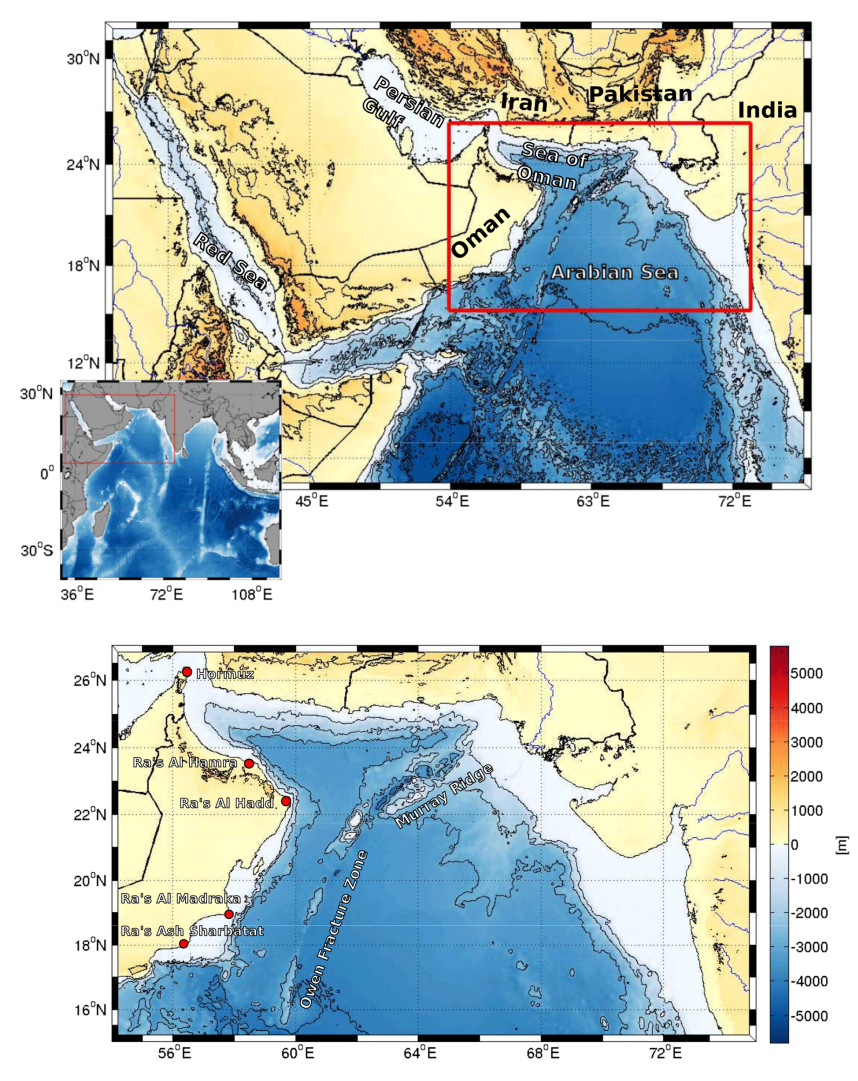

Figure 1. Maps of the northwestern Indian Ocean. Top: area covered by the HYCOM model, including the Arabian Sea and the adjacent gulfs. Bottom: areas of interest in this paper, the Arabian Sea, the Sea of Oman and the main geographical locations.

and $10^{-2} \mathrm{~mm} \mathrm{~s}^{-1}$, during the summer monsoon with the production of very long cold filaments protruding from the coast with a transport from 4 to $8 \mathrm{~Sv}$. Downwellings, mainly along the northeastern coast of the Arabian Sea, along India and Pakistan, have vertical velocities of comparable magnitude, up to $1.5 \times 10^{-2} \mathrm{~mm} \mathrm{~s}^{-1}$.

The surface circulation is also constrained by the seasonal winds, particularly the coastal currents, changing direction with the monsoon. Along the western boundary of the Arabian Sea, the Oman Coastal Current (OCC) flows southwestward in winter and reverses in summer to the northeast. At the Ra's Al Hadd cape, it forms, in summer, an eastwardpropagating jet known as the Ra's Al Hadd jet (see Flagg and Kim, 1998), the most intense feature of the northern Arabian Sea, with velocities of $1 \mathrm{~m} \mathrm{~s}^{-1}$ and an associated transport of 2 to $8 \mathrm{~Sv}$. Along the coast of India, the West Indian Coastal Current (WICC) flows northward during the winter monsoon, with decreasing intensity from 15 to $24^{\circ} \mathrm{N}$ (see Shetye et al., 1991), and southward in summer. Another noticeable feature of the western Indian coast is the presence of coastal Kelvin waves propagating from the Bay of Bengal during the winter monsoon (see Rao et al., 2002).
Offshore, in the interior of the Arabian Sea, the circulation is dominated by mesoscale eddies (see Schott and McCreary Jr., 2001) with sizes of 100-200 km. Some features are recurrent, such as the Ra's Al Hadd jet, composed of a dipole, or also an anticyclone off Ra's Ash Sharbatat, described by Flagg and Kim (1998). The bi-monthly averaged maps of Fig. 2 show the MADT (mean absolute dynamic topography; see the data and methods section for computation) anomaly. Positive anomalies correspond to anticyclonic flows and negative anomalies to cyclonic ones. These maps indicate the presence of recurrent structures from one year to another. The evolution of the MADT over the years is highly periodic and is correlated with the wind stress (see Fig. 3). In the Indian Ocean, variability is observed in a semiannual mode, but also at 135, 120 and 90 days, pointing out the different regime for each season, monsoons or intermonsoons. These spectral peaks are also observed in other fields in this region such as the sea surface temperature. Other periods, at 90, 75 and 60 days, were studied by $\mathrm{Fu}$ (2007).

In the Sea of Oman, the circulation is mainly composed of a western boundary current, intense in summer (up to $0.8 \mathrm{~m} \mathrm{~s}^{-1}$ ), protruding in the Ra's Al Hadd jet, and weak in winter (see Flagg and Kim, 1998). The fall intermonsoon and early winter circulations were studied by Pous et al. (2004b), who observed the boundary current veering around Ra's Al Hadd, flowing southwestward and feeding the OCC. Evidence has been shown of seasonal or higher-frequency variability of the surface circulation in the Sea of Oman, which has been related to atmospheric forcing (seasonal wind stress or the effect of atmospheric cyclones) or to Rossby waves emitted from the eastern boundary (Pakistan and India; see Schott et al., 2009). In particular, mesoscale oceanic dipoles (cyclone + anticyclone), as well as isolated eddies, have been observed in the vicinity of Ra's al Hamra (see L'Hegaret et al., 2013) and off Ra's al Hadd (see Wang et al., 2013).

Another impact of the seasonally steady winds, combined with the net heat flux of the tropical basin, is the high annual evaporation rate. The net evaporation-precipitation budget is large and positive in the Persian Gulf and in the Red Sea. This leads to the generation of water masses with very high salinities (above $40 \mathrm{psu}$ ) in these two basins (see Yao and Johns, 2010a, b, and Bower et al., 2000). The present article focuses on the saline water flowing out of the Persian Gulf.

The Persian Gulf is a very shallow sea with an average depth of about $35 \mathrm{~m}$ and maximum depths around $100 \mathrm{~m}$. Very salty and dense water, Persian Gulf Water (PGW hereafter), is formed via evaporation near the western boundary of the Persian Gulf (see Pous et al., 2015). This water flows through the Strait of Hormuz and spreads in the Sea of Oman and in the Arabian Sea (see Bower et al., 2000, and Fig. 1 for geographical locations and bathymetry). Observations show that the annual mean outflow transport of PGW through the strait is about $0.25 \mathrm{~Sv}$, with little seasonal variation in transport (see Matsuyama et al., 1998, and Johns et al., 2000). But this transport can be affected by short-term pulses related to 

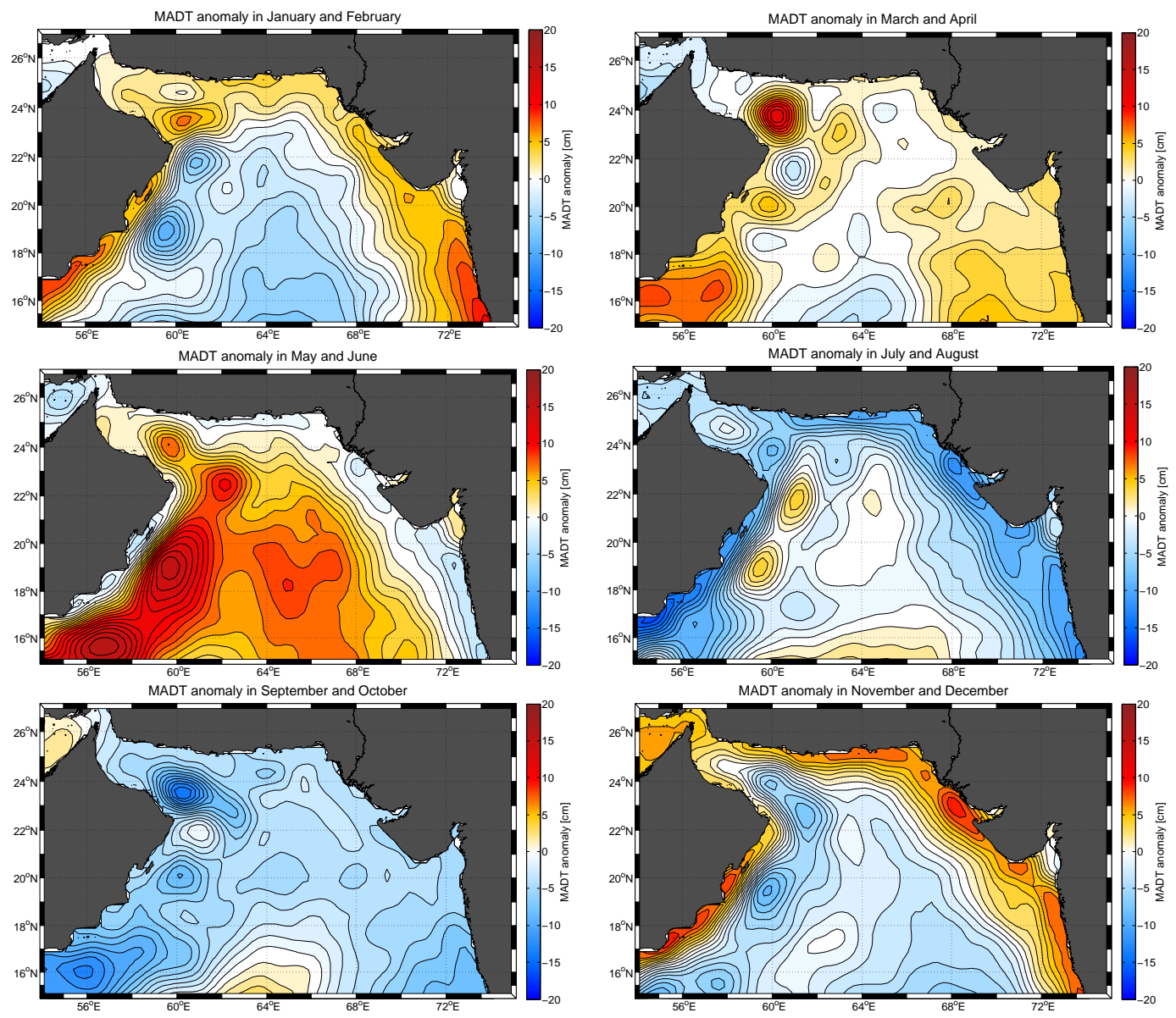

Figure 2. Bi-monthly averaged MADT anomaly (see data and method section for computation) using AVISO data, over years 1992 to 2014. Positive values of the anomaly correspond to an anticyclonic motion, whereas negative ones correspond to a cyclonic motion. Top: January and February (left), March and April (right); center: May and June (left), July and August (right); bottom: September and October (left), November and December (right).

the effect of oceanic cyclones in the Persian Gulf (see Thoppil and Hogan, 2009). Outflowing PGW is colder and saltier in winter (Pous et al., 2004a).

In the northern part of the Sea of Oman, PGW reaches an equilibrium depth between 150 and $250 \mathrm{~m}$ with a density $\sigma_{\theta}$ between 26.3 and 27 (see Fig. 4). The PGW plume tends to deepen away from the straits. It can be found at $250-350 \mathrm{~m}$ depth south of the Arabian Peninsula (see Bower et al., 2000, Pous et al., 2004b, and Carton et al., 2012). Irregularity in the outflow transport and the presence of mesoscale eddies, as well as topographic accidents, can disrupt this deep current, which then sheds fragments of PGW (see L'Hegaret et al., 2013). PGW can form patches and recirculate in the Sea of Oman. More prominently, an intrathermocline eddy of PGW was once observed near the straits, extending towards the middle of the Sea of Oman (see Senjyu et al., 1998).

In the Arabian Sea, the surface layer is occupied by the Arabian Sea High Salinity Water (ASHSW) down to $100 \mathrm{~m}$ depth, presenting high salinity and temperature due to the intense evaporation and low precipitation over the basin, with a $\sigma_{\theta}$ around 23. River inflows are observed in late summer in the western Arabian Sea as a thin surface layer exiting the Indian coast. Below the surface layer, Indian Ocean Central Water is observed with temperature between 15 and $20^{\circ} \mathrm{C}$, and with salinity below $36 \mathrm{psu}$; thus, it has a lighter density than PGW, with $\sigma_{\theta}$ between 25 and 26. The deep and bottom layers are filled by Indian Ocean Deep Water and Antarctic Bottom Water, with $\sigma_{\theta}$ under 27 and 27.5, respectively.

The objective of this paper is twofold. The first objective is to investigate and rationalize the mesoscale variability in the Sea of Oman and Arabian Sea, to characterize the different features, their three-dimensional structures and characteristics, and their seasonal variability. Then the study focuses on the mutual interactions of these features and their interactions with topography and atmospheric fluxes. Second, once the dynamical context has been studied, the characteristics of the PGW are investigated, as well as their seasonality and the various mechanisms of detachment of PGW fragments from 


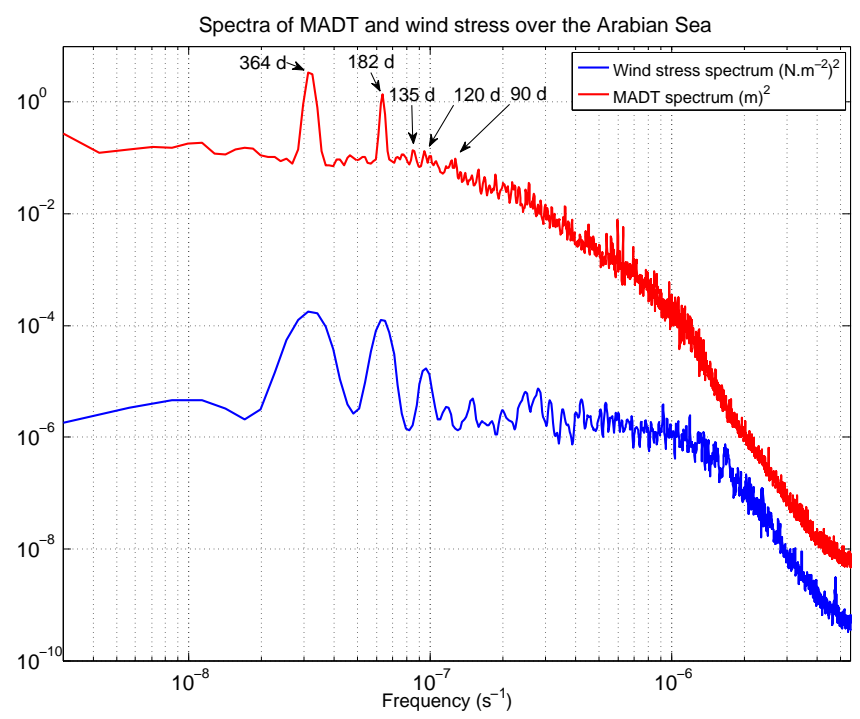

Figure 3. Spectra of 22 years of sea-surface height (SSH) (red, $\left.(\mathrm{m})^{2}\right)$ and 40 years of wind stress (blue, $\left.\left(\mathrm{N} \mathrm{m}^{-2}\right)^{2}\right)$. The spectra are averaged over $15-27^{\circ} \mathrm{N}, 54-75^{\circ} \mathrm{E}$. The periods for the major spectral peaks are indicated.

the plume. To achieve these purposes, a primitive equation model is implemented regionally and the results of the simulations are analyzed in conjunction with synoptic in situ and surface data.

The paper is organized as follows: the model characteristics and the origin and nature of data are first specified; the regional structure and seasonal variability of the water masses and currents in the region are then described from the two independent data sources; the mesoscale structures and their interactions are characterized and, finally, the impact of these structures on the PGW outflow is quantified.

\section{Data, model and methods}

The numerical simulations were performed with the Hybrid Coordinate Ocean Model (HYCOM) (see Chassignet et al., 2007). HYCOM is a primitive equation, hybrid coordinate model (isopycnal and $z$ ). The model variables are discretized on a horizontal Arakawa C-grid. The horizontal resolution is here $5 \mathrm{~km}$ and the model has 40 vertical levels. The model simulates both of the basins of evaporation, the Red Sea and the Persian Gulf, and extends to the south of India (see Fig. 1). The simulation is initialized with a state given by a lower-resolution global model (MERCATOR PSY3, $1 / 4^{\circ}$ ) and is forced by realistic atmospheric fields (from the French Met Office: METEO FRANCE) cycling over 2011. The open boundaries, south and west, south of India, are also forced in salinity, temperature and currents by MERCATOR. The tidal forcing is provided by Topex and is included as a boundary condition. The vertical mixing is a K-profile parameterization (KPP; see Large et al., 1994). The model provides a PGW slightly lighter with $\sigma_{\theta}=26$ instead of 26.3 due to higher temperature (see Fig. 4). Lighter water from river discharge is poorly sampled by the ARGO floats that most often drift at $1000 \mathrm{~m}$ depth. Indeed, this water mass is essentially confined above the shallow shelves of the western India coast. Nevertheless, the water masses show no other difference between HYCOM and ARGO profiles. An 11-year simulation starting in 2011 was produced. The first 5 years correspond to the spin-up of the model and were discarded. The spin-up was considered achieved when the mesoscale circulation was well established and the properties of the main water masses reached their typical values. Only the last 6 years of the simulation were analyzed; in our timeline, they are denoted 6 to 11 .

To study the thermohaline variability over the seasons, we used a modified GDEM (generalized digital environmental model) climatology. GDEM is a monthly climatology constructed from MOODS (Master Oceanographic Observational Data Set) profiles, with 72 vertical levels and a $1 / 4 \times 1 / 4^{\circ}$ horizontal resolution (see Carnes, 2009 , for climatology construction). This climatology provided a good description of the Arabian Sea and the bordering gulfs and seas, particularly the Sea of Oman. To improve the horizontal resolution and to follow the different water masses, we added profiles from ARGO floats. These long-lived drifters provide high-quality profiles for temperature and salinity. We used the ANDRO data set for floats released before 2010 and the CORIOLIS (France) and INCOIS (India) databases for later ones. Over 100 floats were found to be drifting north of $18^{\circ} \mathrm{N}$ in the Arabian Sea between 2002 and 2014, which corresponds to 550 to 600 profiles per month, on average.

The surface fluxes that were used for analysis were issued from a monthly meteorological model reanalysis by ECMWF. This reanalysis provided monthly climatologies of wind, heat, evaporation and precipitation fluxes over 40 years with a resolution of $0.7^{\circ}$. The horizontal resolution is low but sufficient to resolve the mesoscale at these latitudes, and this provided a data set on a long period of time, necessary to compute a climatology. We also used altimetric data from AVISO over 22 years, from 1992 to 2014. From the MADT, the instantaneous spatial average was subtracted to obtain MADT anomalies.

Different parameters are calculated from the results of the HYCOM simulation. The deformation is the sum of the squared strain and shear, $\sigma=\sigma_{\text {strain }}^{2}+\sigma_{\text {shear }}^{2}$ with $\sigma_{\text {strain }}=$ $\frac{\partial V}{\partial x}+\frac{\partial U}{\partial y}$, and $\sigma_{\text {shear }}=\frac{\partial U}{\partial x}-\frac{\partial V}{\partial y}$ the shear. The anomaly of Ertel potential vorticity (PVE) is computed from the total PVE

$\mathrm{PVE}=-\frac{1}{\rho_{0}} \cdot\left(\left[f+\frac{\partial V}{\partial x}-\frac{\partial U}{\partial y}\right] \cdot \frac{\partial \rho}{\partial z}-\frac{\partial V}{\partial z} \cdot \frac{\partial \rho}{\partial x}+\frac{\partial U}{\partial z} \cdot \frac{\partial \rho}{\partial y}\right)$

from which we substract a PVE value calculated out of the eddies and jets. 

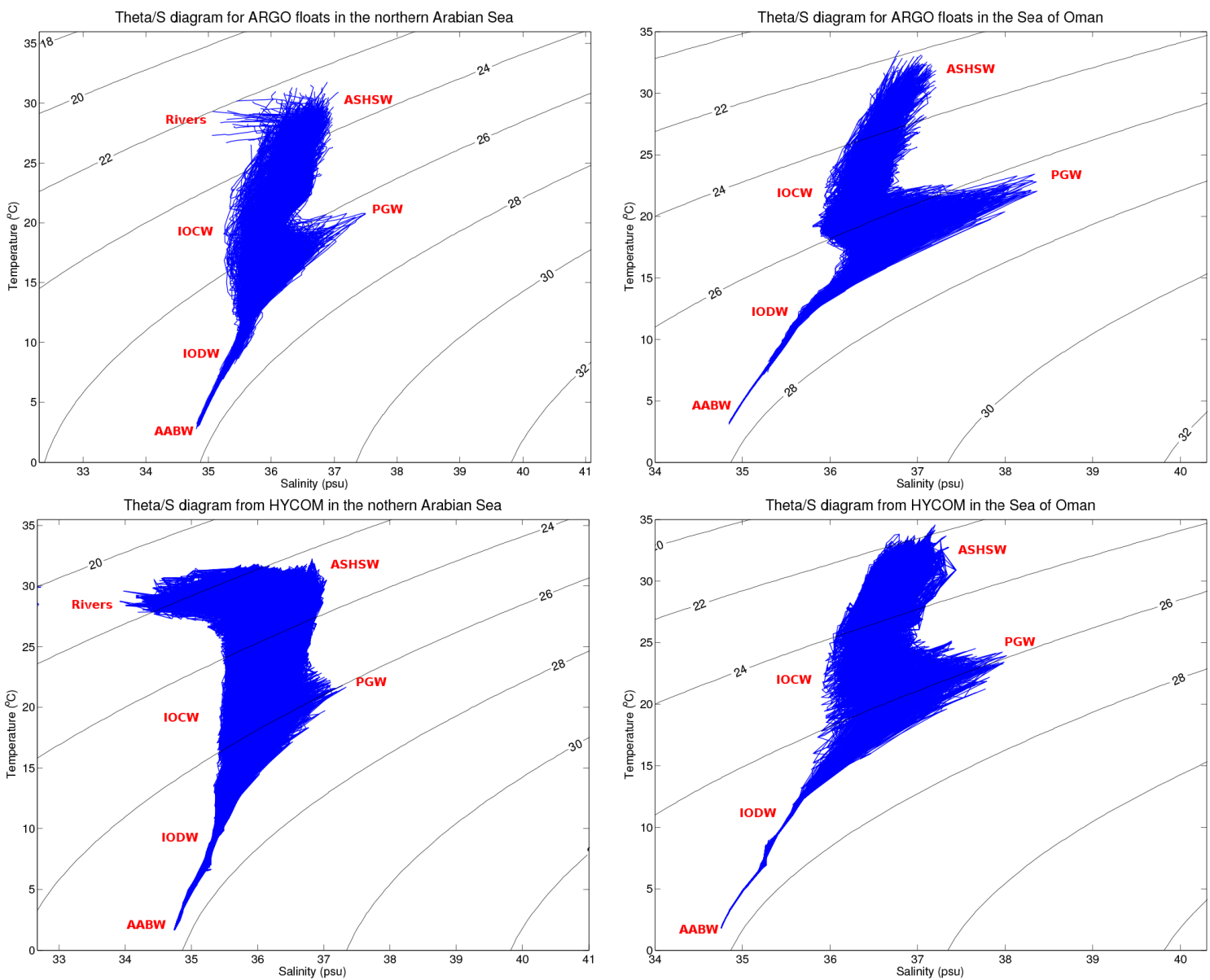

Figure 4. Temperature versus salinity diagram in the Sea of Oman (left) and in the northern Arabian Sea (right), from the ARGO float (top) and the HYCOM simulation (bottom). The different water masses are Arabian Sea High Salinity Water (ASHSW), Persian Gulf Water (PGW), Indian Ocean Central Water (IOCW), Indian Ocean Deep Water (IODW), and Antarctic Bottom Water (AABW).

\section{Mesoscale structures, formations and evolutions}

Three mesoscale structures are presented hereafter: coastal currents, eddies and waves. Their formations, structures, evolutions and seasonality are studied in the Arabian Sea and in the Sea of Oman.

\subsection{Coastal currents}

The first type of mesoscale structure studied here is the coastal current. The monsoonal winds induce a net Ekman transport offshore in summer and shorewards in winter along the northern and western coasts of the basin. This leads, respectively, to a lowering (with the upwellings) or to an uplifting of the sea surface in these regions, with the formation of geostrophically balanced coastal currents. A contrast is observed between the coasts and the interior of the basin in Fig. 2. From May to September, the MADT anomaly is negative along the coast, while it is positive in the center of the basin; the situation reverses in November until January.
This coastal current is about $150 \mathrm{~km}$ wide, with an associated velocity up to $0.7 \mathrm{~m} \mathrm{~s}^{-1}$ near the strongest eddies and about $0.3-0.4 \mathrm{~m} \mathrm{~s}^{-1}$ elsewhere, directed southwest in Fig. 5 (center), in the HYCOM simulation during the winter monsoon. Offshore, northeastward velocities are observed, and the map of the Ertel potential vorticity anomaly indicates a change of sign between the offshore and coastal values. The likeliness of the barotropic instability can be estimated for this structure by evaluating the RayleighKuo criterion, which states that $\beta-\frac{\partial^{2} U_{\mathrm{h}}}{\partial y^{2}}$ changes sign in the region if the flow is unstable; $U_{\mathrm{h}}$ is the horizontal velocity. Here, taking into account the slope of the current, $U_{\mathrm{h}} / L^{2}$ and $\beta \sqrt{2} / 2$ have the same order of magnitude of $1.3 \times 10^{-11} \mathrm{~m}^{-1} \mathrm{~s}^{-1}$, with $U_{\mathrm{h}}=0.3 \mathrm{~m} \mathrm{~s}^{-1}, L=150 \mathrm{~km}$ and $\beta=2 \times 10^{-11} \mathrm{~m}^{-1} \mathrm{~s}^{-1}$. Thus, barotropic instability can occur for the coastal current.

The cross section in Fig. 6 shows that, in the upper few hundred meters, an inversion of the Ertel potential vorticity anomaly occurs vertically. The possibility of baroclinic instability can be assessed for this current using a simple two- 

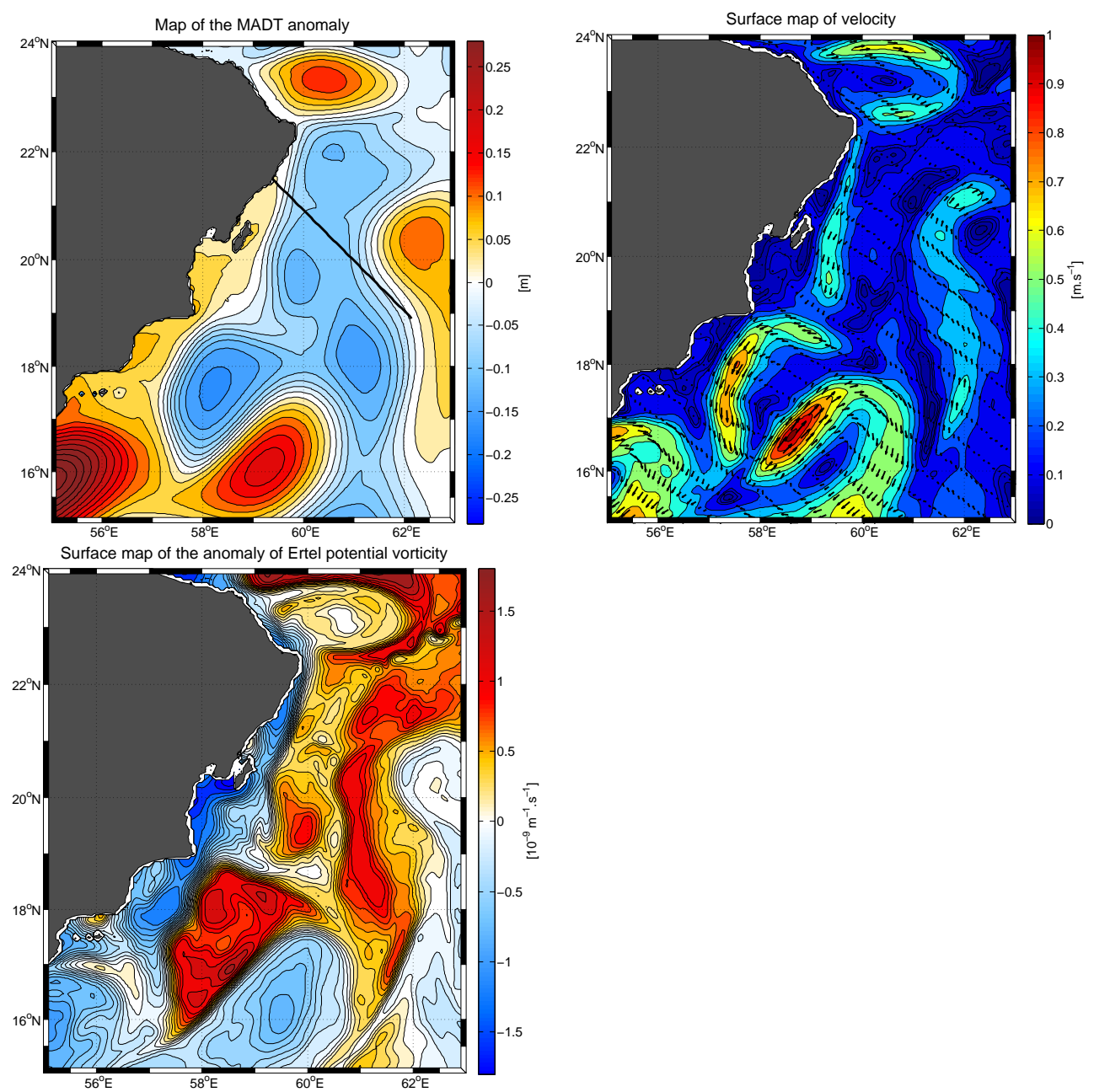

Figure 5. Maps from HYCOM during the winter monsoon, showing the presence of the coastal current: (top left) MADT anomaly; (top right) surface velocity; (bottom) anomaly of Ertel potential vorticity. The anomalies of altimetry and Ertel potential vorticity have an opposite sign along the coast, in the current, and offshore. The position of the cross section is indicated on the upper left map.

layer Phillips model. With two equally thick layers and opposite surface and deep flows (see Vallis, 2006), the condition for existence of baroclinic instability is that the vertical shear of horizontal velocity $U_{\mathrm{s}}$ be larger than $\beta R_{d}^{2} / 4$. Here $R_{d} \approx 40 \mathrm{~km}$, so that the threshold for velocity shear is about $0.01 \mathrm{~m} \mathrm{~s}^{-1}$. Thus the possibility of baroclinic instability for this coastal current is validated. Maximum baroclinic instability is obtained under such conditions for $\lambda=2 \pi R_{d} / 1.8 \approx$ $140 \mathrm{~km}$ (theoretical value for a large shear), which is comparable with the largest western eddy diameters in observations (approximately $200 \mathrm{~km}$ ). Note that a similar estimate is obtained with the Eady model, $\lambda \approx 4 R_{d}$, corresponding to a most unstable wavelength of $160 \mathrm{~km}$ (see also Smith, 2007).

Finally, the growth rate of such unstable waves is $\sigma=$ $0.3 U_{\mathrm{s}} / R_{d}$ in the Phillips model, or about $1 / 5$ days, with $U_{\mathrm{s}}=0.3 \mathrm{~m} \mathrm{~s}^{-1}$. The Eady model gives the same expression and result. On MADT maps (see Fig. 7), eddies are fully formed within 20 to 25 days after the appearance of the me- anders. This duration is about $4 \sigma^{-1}$ (or four linear periods of instability), which takes into account the time necessary for wave growth and nonlinear interactions. Such a duration was commonly observed for eddy formation and detachment from an unstable jet in previous studies of baroclinic instability (see Flierl et al., 1999). This instability of the coastal jets leads to the second type of mesoscale feature in the basin, the mesoscale eddies.

\subsection{Mesoscale eddies}

Mesoscale eddies are the most intense dynamical structures in the northern Arabian Sea. They are observed mainly west of $65^{\circ} \mathrm{E}$ with increasing diameters from east to west, from 100 to $200 \mathrm{~km}$ (see Figs. 2 and 8). The strongest eddies are observed along the coasts or aligned along the coastal currents. North of $15^{\circ} \mathrm{E}$ and south of Ra's Al Hadd, four intense eddies are found along the coasts; two to four eddies are ob- 

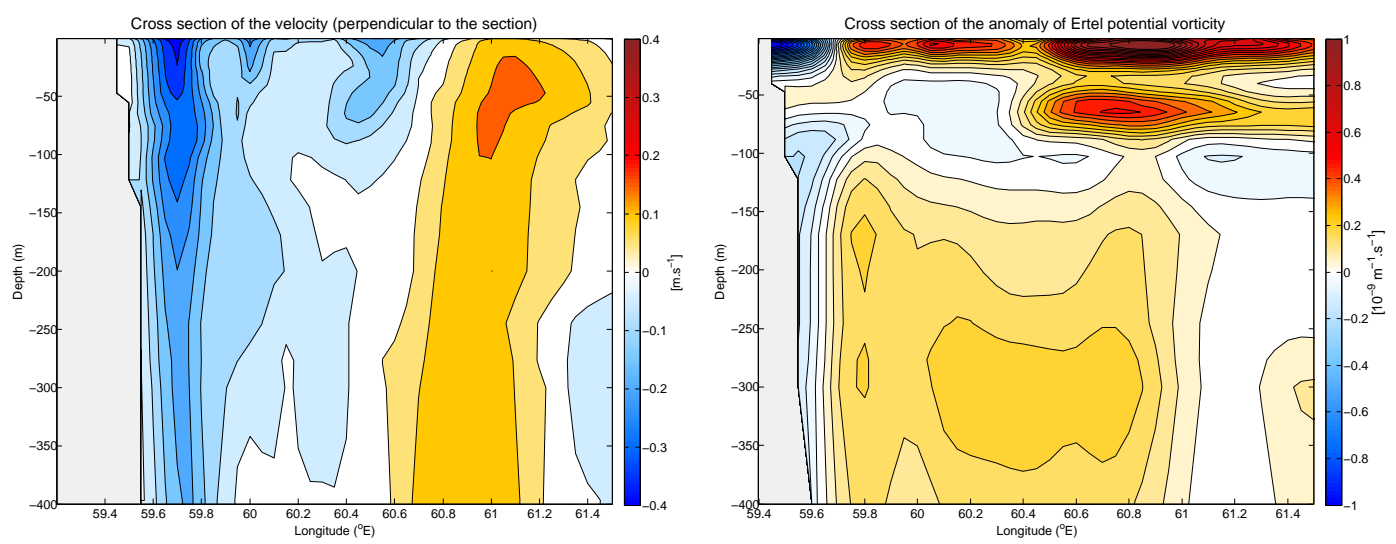

Figure 6. Section across the coastal current during the winter monsoon (from HYCOM): (left) velocities across the section (positive toward the northeast); (right) anomaly of Ertel potential vorticity. A vertical influence of the surface structures is observable. An inversion of the Ertel potential vorticity sign occurs between the surface and depth.

served in the Sea of Oman. These structures have a seasonal recurrence, as seen in Fig. 2, with dipoles forming off $\mathrm{Ra}$ 's $\mathrm{Al}$ Hadd in summer, or off Ra's Al Hamra, in the Sea of Oman, in spring.

As seen in the previous section, their formation is linked to the destabilization of the coastal current, with the formation of cyclonic eddies in summer (anticyclonic in winter) along first the Iranian coast, then the Omani coast. The amplification of these eddies can result from a localized, steady and strong wind stress curl forcing. This occurs in particular in the Sea of Oman and along the western coast of the basin, for all seasons, and furthermore along the Indian coast in summer. The wind-induced relative vorticity is expressed as $\Delta \xi=\frac{\vec{k} \cdot \vec{\nabla} \wedge \vec{r}}{\rho_{0} H} \Delta t$ (see Dong et al., 2007). The strongest values are found near these coasts and in the Sea of Oman with an order of magnitude of $2.5 \times 10^{-6} \mathrm{~s}^{-1}$, positive in summer, negative the rest of the year. Comparatively this is about $35 \%$ of the relative vorticity calculated from the sea surface height, with $7 \times 10^{-6} \mathrm{~s}^{-1}$ for the mesoscale eddies. As shown in L'Hegaret et al. (2013), in spring to early summer near Ra's al Hadd, the wind veers clockwise at this period and imparts anticyclonic vorticity to the ocean, thus reinforcing an anticyclonic eddy. A further amplification of this vorticity was then interpreted by the same authors as the result of the interaction with an incoming upwelling Rossby wave; this process will be studied in more detail here.

The eddies are intensified in the upper water column, with velocities up to $0.7 \mathrm{~m} \mathrm{~s}^{-1}$ from the surface down to $150 \mathrm{~m}$ depth (see Fig. 9). The velocity section shows the vertical influence of those eddies. From the HYCOM simulation, correlation between the surface and at-depth velocities can be estimated. Figure 10 (up) shows the correlation coefficient between the surface and $600 \mathrm{~m}$ depth velocities. Strong correlations are found around the eddies, with the exception of their centers, where tilting can slightly modify their axes. Zooming in on a specific eddy, the attenuation coefficient can be retrieved; thus, $70 \%$ of the surface velocity intensities are recovered at $300 \mathrm{~m}$ depth, $50 \%$ at $500 \mathrm{~m}$, and up to $30 \%$ at $1000 \mathrm{~m}$. This vertical influence was also seen in the strong correlation between float drifts at $700 \mathrm{~m}$ and the surface geostrophic velocities (see L'Hegaret et al., 2013). These mesoscale eddies induce an intense deformation field associated with their high and sheared velocities, having thus an impact on the water masses at depth.

Under the anticyclone and the cyclone, the vertical spacing between isopycnals shrinks and widens successively with a stronger deviation in the first $300 \mathrm{~m}$ (see Pous et al., 2004b). These isopycnal deviations have an influence on the water masses. The surface water, ASHSW, is sampled in the first $150 \mathrm{~m}$; below, the IOCW (Indian Ocean Central Water) is colder and fresher with salinity under $36 \mathrm{psu}$, and between 200 and $300 \mathrm{~m}$ the PGW is observed. The core of the IOCW is thinner in HYCOM than in the in situ observations because of the depth of the PGW, which is found deeper than in the model. The eddies can deepen or elevate the depth of the PGW. Between the eddies, layers of ASHSW and IOCW wrap around the cyclone, injecting different water masses inside the eddy. The stratification is maximum at the depth of the PGW core and near the injection around the eddies.

\subsection{Rossby waves}

Time vs. longitude diagrams of the MADT anomaly from AVISO (see Fig. 11) reveal westward propagative anomalies from the Indian coast. Some of these anomalies have been identified as Rossby waves (see L'Hegaret et al., 2013) with a wave speed of $c=-\beta R_{d}^{2}$ of $21 \mathrm{~cm} \mathrm{~s}^{-1}$ and with a wavelength of about $210 \mathrm{~km}$. These waves have also been observed more southwards by Heffner et al. (2008). The Hovmoller diagrams from both AVISO and HYCOM point out the strong reversal of positive and negative anomalies along the eastern side of the basin followed by wave emission. Penetration of Kelvin waves along the coast of India from the 

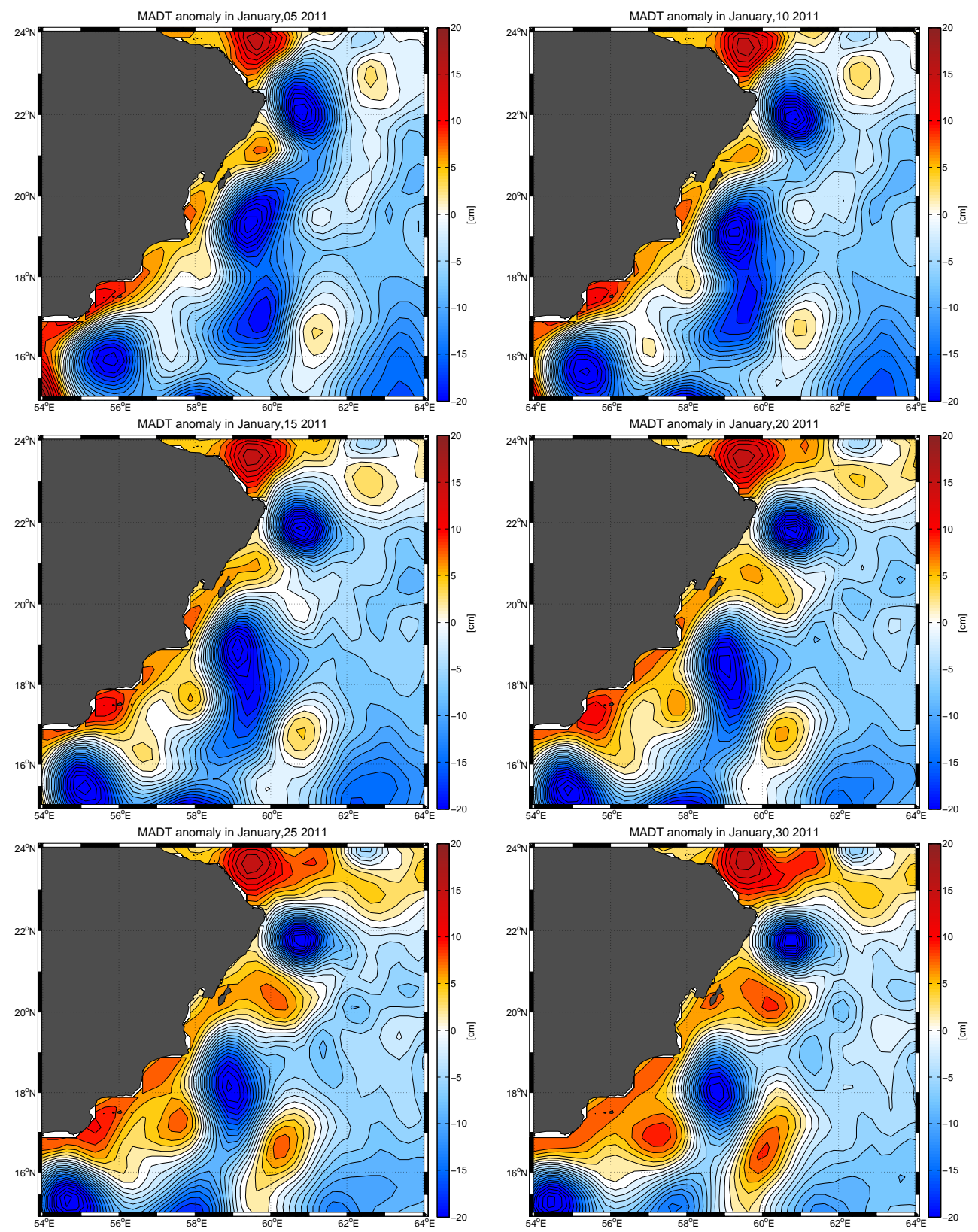

Figure 7. Maps of the MADT anomaly from AVISO, during the winter monsoon, in January 2011, every 5 days. The first map shows the presence of meanders on the coastal current, then forming coherent mesoscale eddies at $18^{\circ} \mathrm{N}, 58^{\circ} \mathrm{E}$ on $20 \mathrm{January}$ and at $18^{\circ} \mathrm{N}, 58^{\circ} \mathrm{E}$ on 30 January.

Bay of Bengal is known to emit Rossby waves in the southern part of the basin. A comparison between years of strong emission of Rossby waves (Rao et al., 2002) and the northern Hovmoller diagram from AVISO emphasizes the fact that Kelvin waves end south of $18^{\circ} \mathrm{N}$.

The Hovmoller diagram at $16^{\circ} \mathrm{N}$ shows this alternation of positive and negative anomalies twice a year, whereas at $20^{\circ} \mathrm{N}$ other wave trains are observed. Using the Fu and Qiu (2002) method, it is possible to estimate the ability of both the wind stress and coastal Kelvin waves to set Rossby waves. Figure 12 presents the correlation coefficients between the MADT evolution from AVISO with the Rossby waves created by the wind stress field (top) and the coastal waves (bottom). These maps indicate correlation coefficients above 0.6 with the wind forcing from 20 to $22^{\circ} \mathrm{N}$ and from 23 to $25^{\circ} \mathrm{N}$; nevertheless, below $20^{\circ} \mathrm{N}$, the winds at the eastern coast have a higher capacity to set up Rossby waves. 


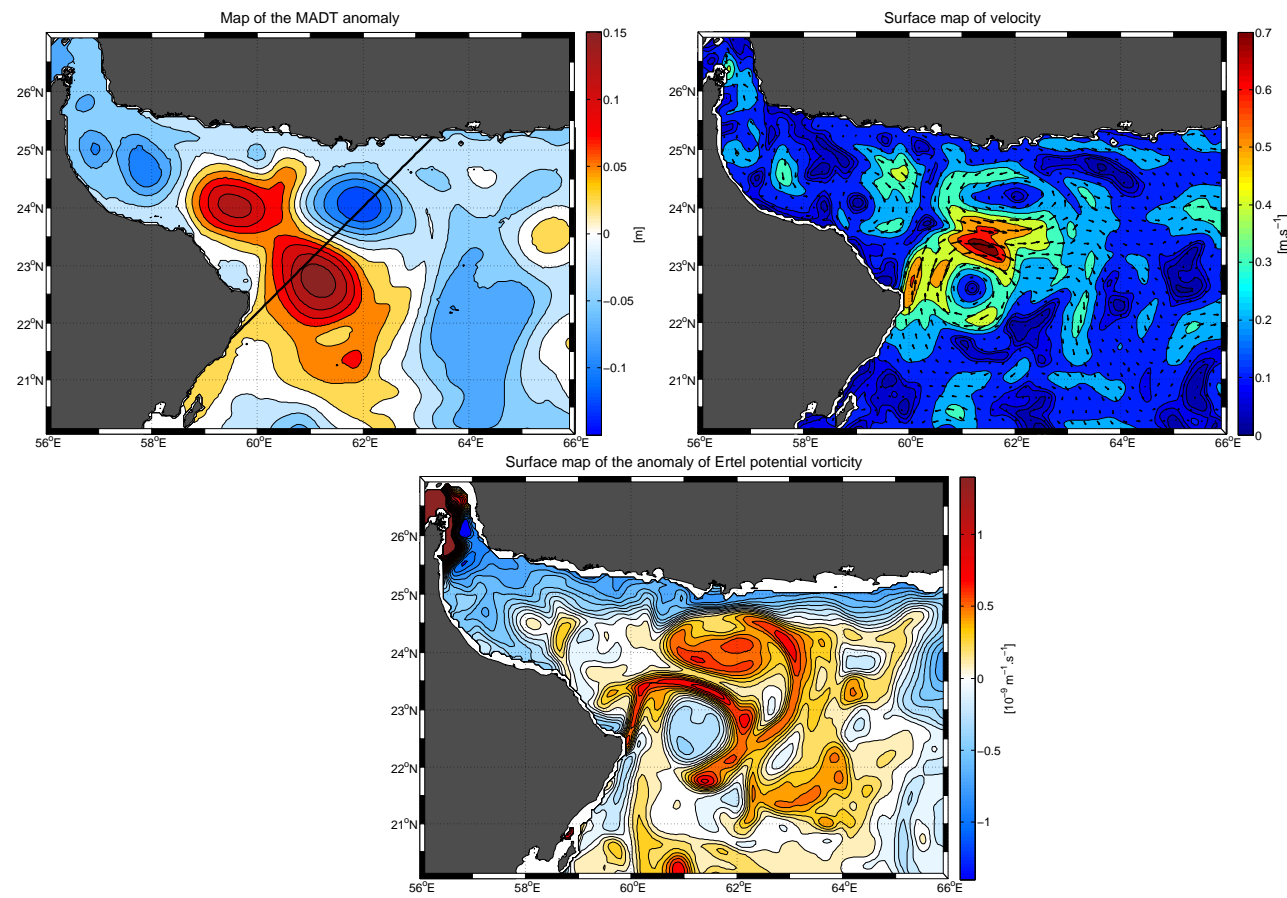

Figure 8. Maps from HYCOM showing the presence of mesoscale eddies: (upper left) MADT anomaly; (upper right) surface velocity; (lower panel) anomaly of Ertel potential vorticity. The anomalies of Ertel potential vorticity have an opposite sign inside and at the periphery of the eddies. This is primarily seen around the anticyclone north of Ra's Al Hadd, the cyclone interacting with the coastal negative anomaly of Ertel potential vorticity.
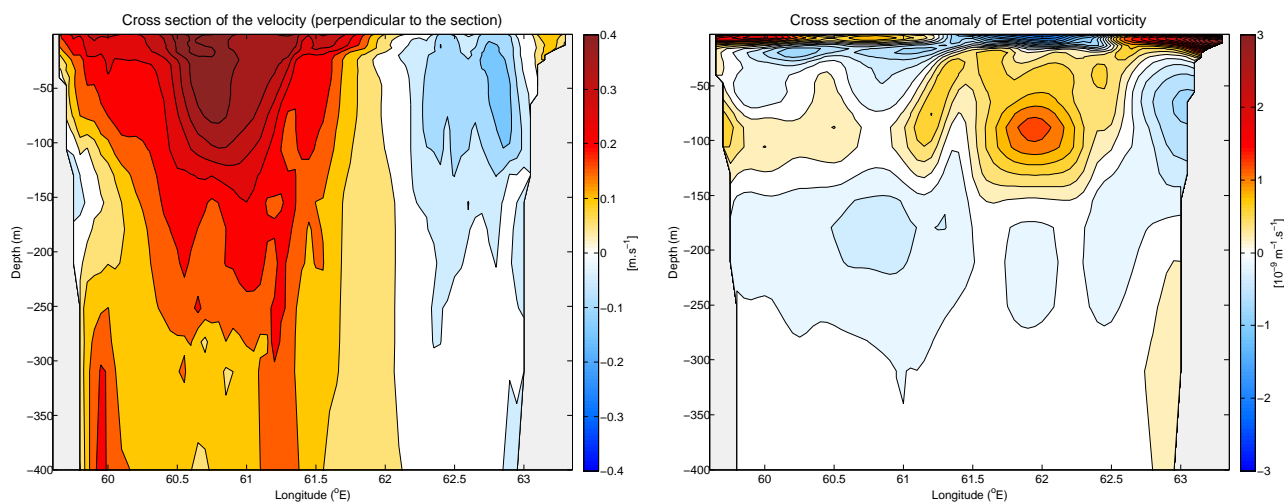

Figure 9. Section across the eddies during the winter monsoon (from HYCOM): (left) velocities across the section (positive toward the southeast); (right) anomaly of Ertel potential vorticity. The core of the eddies is intensified in the first $150 \mathrm{~m}$.

\section{Interactions of the mesoscale structures}

Three different mesoscale features were presented in the previous section: the coastal current, the eddies and the Rossby waves. Hereafter, interactions of these structures with each other and with the atmospheric fluxes are studied.

\subsection{Rossby wave interactions}

A noticeable feature is the intensification of the surface signature in the Hovmoller diagram at $20^{\circ} \mathrm{N}$ around $64-68^{\circ} \mathrm{E}$ (see Fig. 11, right). Furthermore, the maps of correlation show low coefficients in the western part of the basin for the Rossby waves forced by coastal waves, west of the topographic ridge and in a region where the mesoscale eddies are more intense. Hereafter, interactions of Rossby waves with the topography and with a dipole of mesoscale eddies are investigated. 


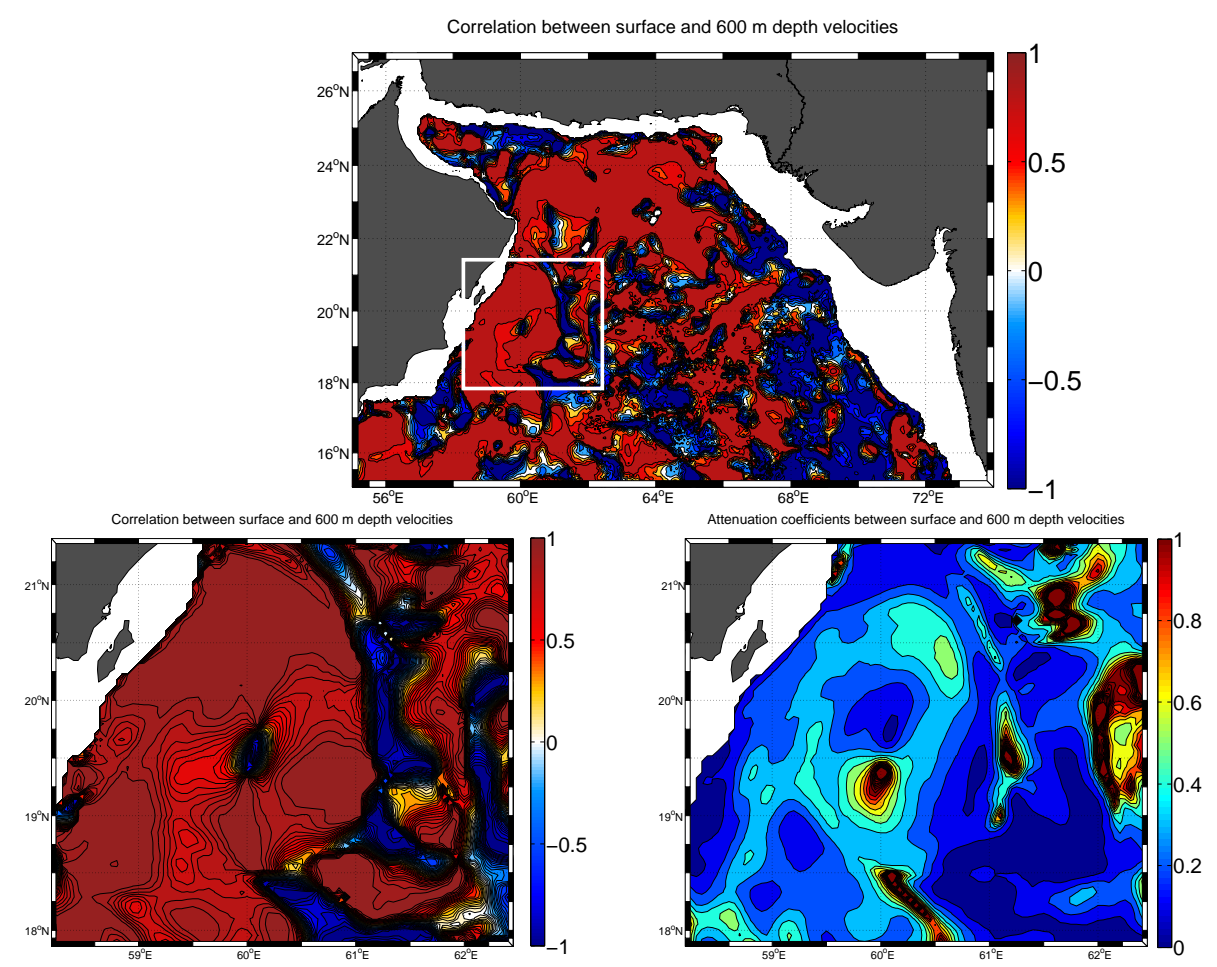

Figure 10. Maps from HYCOM: (top) correlation coefficient between surface and $600 \mathrm{~m}$ depth velocities; (bottom, left) zoom on a mesoscale eddy; (bottom, right) attenuation coefficient between the surface and $600 \mathrm{~m}$ depth velocities: up to $50 \%$ of the intensity is observed.
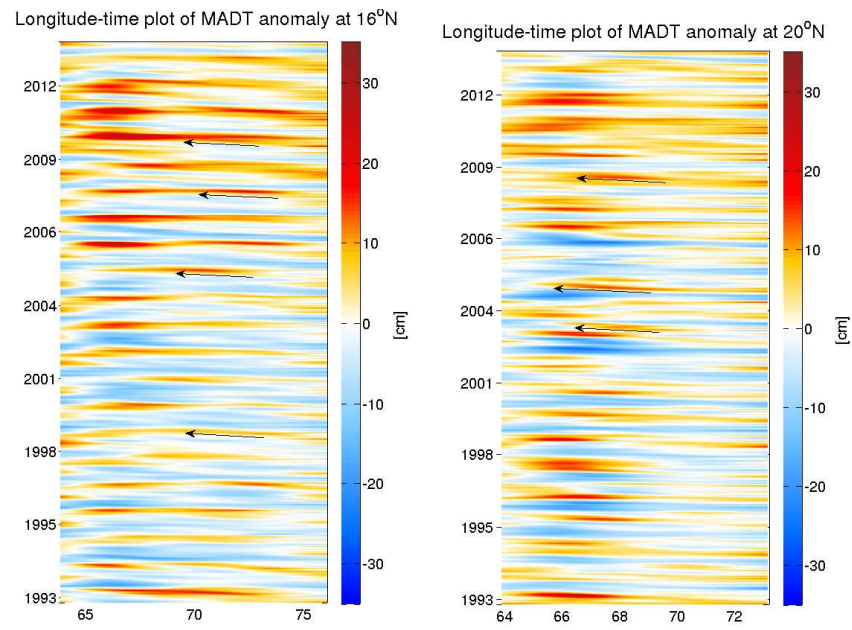

Figure 11. Hovmoller diagram in longitude vs. time for the MADT anomaly from AVISO at $16^{\circ} \mathrm{N}$ (left) and $20^{\circ} \mathrm{N}$ (right).

\subsubsection{Rossby waves over a seamount}

These waves along $21.5^{\circ} \mathrm{N}$ interact with a topographic ridge between 62 and $64^{\circ} \mathrm{E}$. Along $24^{\circ} \mathrm{N}$ as well, anomalies intensify west of $64^{\circ} \mathrm{E}$. To study the influence of topography on Rossby waves, a numerical model of a two-dimensional flow in a bi-periodic domain is used; Rossby waves are initialized with a wavelength of $180 \mathrm{~km}$, propagating over a seamount

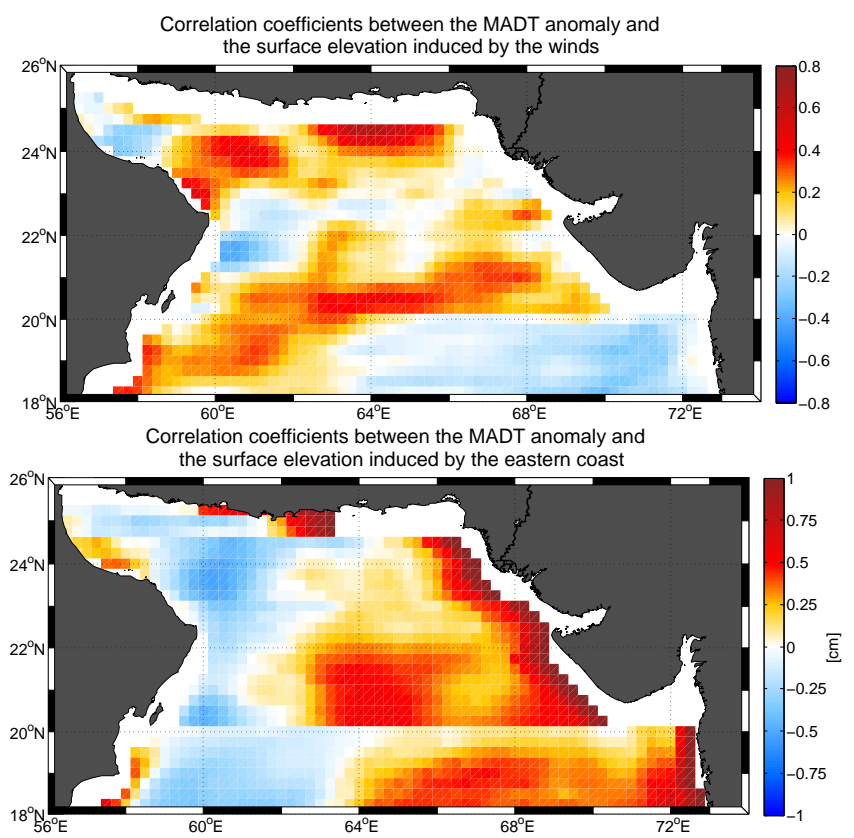

Figure 12. Correlation between the MADT from AVISO and the surface elevation anomaly created by the wind stress (top) and by the waves along the eastern coast (bottom) using the Fu and Qiu (2002) method. 
with a $30 \mathrm{~km}$ radius. Figure 13 shows the flow evolution of the relative vorticity. The Rossby waves deform over the seamount and create a meridional dipole propagating westward; the analytical solution for the flow over the seamount is calculated in the Appendix. It indeed shows the creation of a dipolar perturbation. These results correspond to the propagation observed in the Hovmoller diagram, with a weak anomaly of large wavelengths on the eastern side of the topographic ridge, followed by stronger and shorter anomalies on the western side. The shorter signal is related to the more chaotic nature of the vorticity field resulting from the waveseamount interaction. The stronger amplitude to the west of the ridge, in the Hovmoller diagram (Fig. 11), is due to the vortex-vortex and vortex-wind stress interaction.

\subsubsection{Interaction between Rossby waves and a dipole}

With the same numerical model, the evolution of a Rossby wave, interacting with a dipole, is studied here in order to understand whether the wave train, propagating westward and encountering the eddies, can reinforce them or not. Different configurations were studied, with different vorticities of the dipole and of the Rossby wave. In the case where the Rossby wave is the strongest, the dipole is either destroyed or deflected northward. In Fig. 14, the Rossby waves deform to recirculate and form eddies, and then merge with the original dipole.

Therefore, the earlier interpretation of direct reinforcement of an anticyclone by a Rossby wave (see L'Hegaret et al., 2013) is not supported by the present simulations. It is in fact a two-step process where the original wave has to deform before it can reinforce the original dipole. Also, the interaction of the dipole with the Rossby wave generates a circular envelope of potential vorticity around it. The sign of the envelope changes at the northern and southern edges of the dipole, with consequent squeezing of the dipole and enhancement of its translational velocity (also observed by Couder and Basdevant, 1986).

\subsection{Eddy merger along the Omani Coastal Current}

The northwestern Arabian Sea and the Sea of Oman are filled with mesoscale eddies, originating from the instability of the coastal current, or from the unstable evolution of Rossby waves. These eddies tend to propagate westward, mostly as trains of structures, until they reach the Omani coast. An exception to this westward propagation of eddies is the existence of quasi-stationary eddies near the mouth of the Sea of Oman $\left(25^{\circ} \mathrm{N}\right)$ or near Ra's Madrakah $\left(19^{\circ} \mathrm{N}\right)$. These eddies can interact in different ways. Indeed, two eddies with opposite-signed vorticity can pair and form a (propagating) dipole. Two eddies with like-signed vorticity can merge if they are close enough.

Figure 15 shows an occurrence of eddy merger near the coast of Oman in summer. The MADT anomaly shows that this merger occurs in the presence of a coastal current, which induces a deformation field on these eddies. In the absence of an external deformation field, eddy merger is known to produce final structures larger than the initial eddies. But in the presence of external shear and strain, filaments are torn away from the eddies and the final structure has a radius similar to that of the initial eddies (about $100 \mathrm{~km}$ ).

Deformation is maximal at the eddy periphery and between them, while vorticity is maximal in the eddy cores; this latter region is about $50 \mathrm{~km}$ in diameter and is characterized by a strong local recirculation. In the eddy cores, the Ertel potential vorticity anomaly is negative, while it is positive in the coastal current. Also, a strip (or a filament) of positive Ertel PVE is advected between the two initial eddies and around the final (merged) eddy. This final eddy has thus an R-structure as described by Morel and McWilliams (1997), whereby the vortex is isolated by a shield of opposite signed, mostly relative, vorticity in its periphery.

The strong ejection of fluid from the merging eddies, into smaller structures, is associated with kinetic energy dissipation and a weaker efficiency of the merging process.

\subsection{Eddy-surface fluxes (net heat and wind) interaction}

Around the year, the surface fluxes have a strong influence on the basin circulation. The wind has an influence on the sea level anomaly through the wind work $P=\vec{\tau} \cdot \vec{U}_{\mathrm{g}}$ with $U_{\mathrm{g}}$ the geostrophic speed at the surface. Roquet et al. (2011) decomposed the wind work into a downward flux of a pressure work term and a lateral divergence term. Only the first term $P_{\text {down }}$ can locally modify or create sea surface anomalies. Following Vic et al. (2014), this quantity is integrated here over a mesoscale eddy,

$P_{\text {down }}=-\rho_{0} g\left\langle\eta \vec{\nabla} \wedge\left(\frac{\vec{\tau}}{\rho_{0} f}\right)\right\rangle$,

with $\langle\rangle=.\frac{1}{S} \iint_{S} . d S$, and $S$ the surface of the eddy where the MADT anomaly $\eta$ is larger than $5 \mathrm{~cm}$ (this value was chosen to have a closed, delimited contour around the structure).

Haney et al. (2001) studied the transfer of kinetic energy from the vertical shear flow to the vertical mean flow in California Current eddies, that is, the baroclinic to barotropic energy conversion (see also Vic et al., 2014). The velocity is decomposed as $U=\bar{u}+u^{\prime}$ with $\bar{u}$ the barotropic flow and $u^{\prime}$ the baroclinic. The (.) is the vertical mean defined as (.) $=\frac{1}{H} \int_{-H}^{0} \cdot \mathrm{d} z$ where $H$ is the depth to the surface where more than $50 \%$ of the kinetic energy is contained. The kinetic energy conversion $\left\{K^{\prime} \bar{K}\right\}$ is the sum of two terms

$$
\left\{K^{\prime} \bar{K}\right\}_{\xi}=\rho_{0} H\left\langle\overline{\nabla \wedge \overrightarrow{u^{\prime}}\left(\bar{u} v^{\prime}-\bar{v} u^{\prime}\right)}\right\rangle
$$

and

$$
\left\{K^{\prime} \bar{K}\right\}_{\nabla}=-\rho_{0} H\left(\overrightarrow{\nabla \cdot \overrightarrow{u^{\prime}}\left(\bar{u} u^{\prime}+\bar{v} v^{\prime}\right)}\right) .
$$



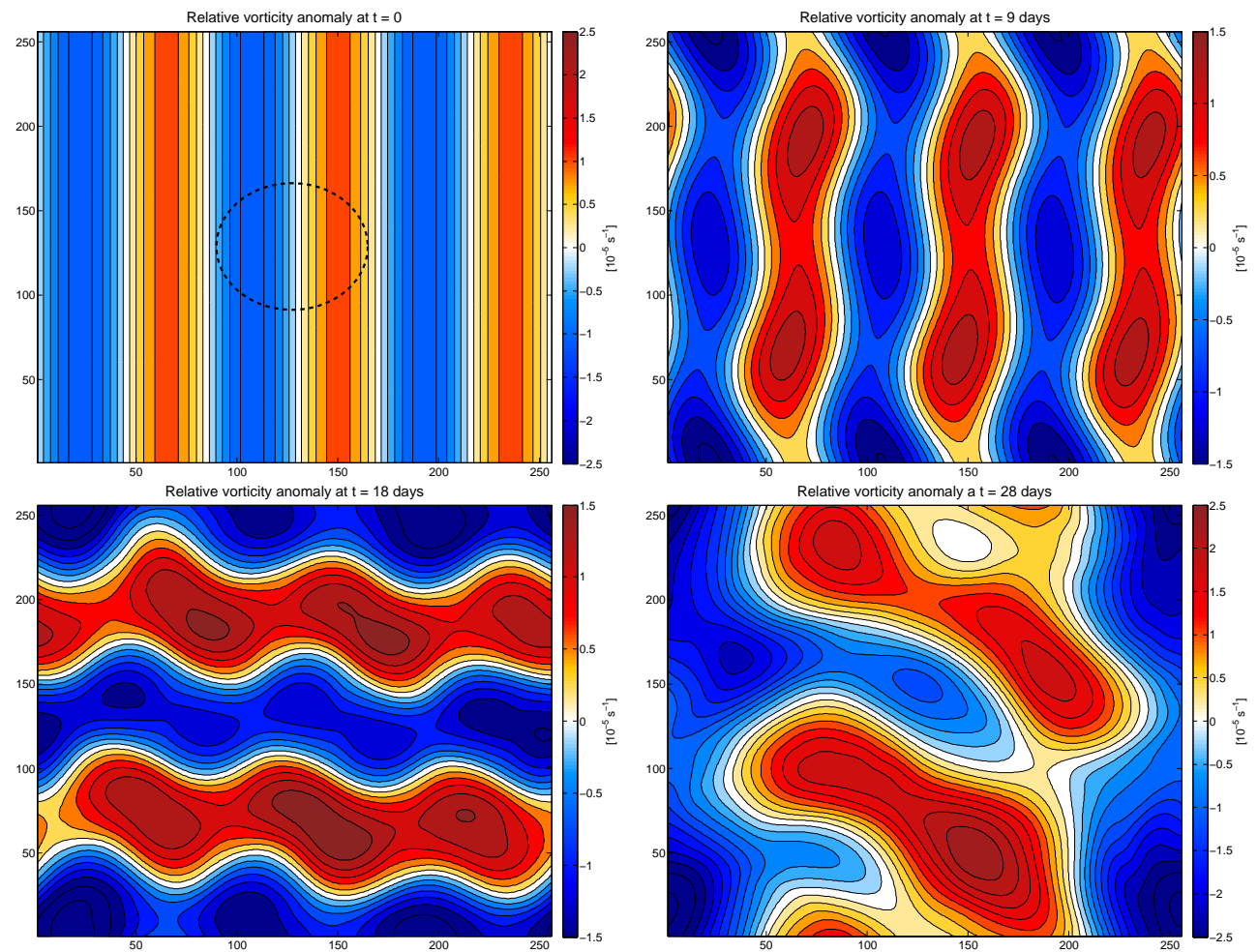

Figure 13. Evolution of the relative vorticity of a Rossby wave over a seamount, located at the middle of the map.
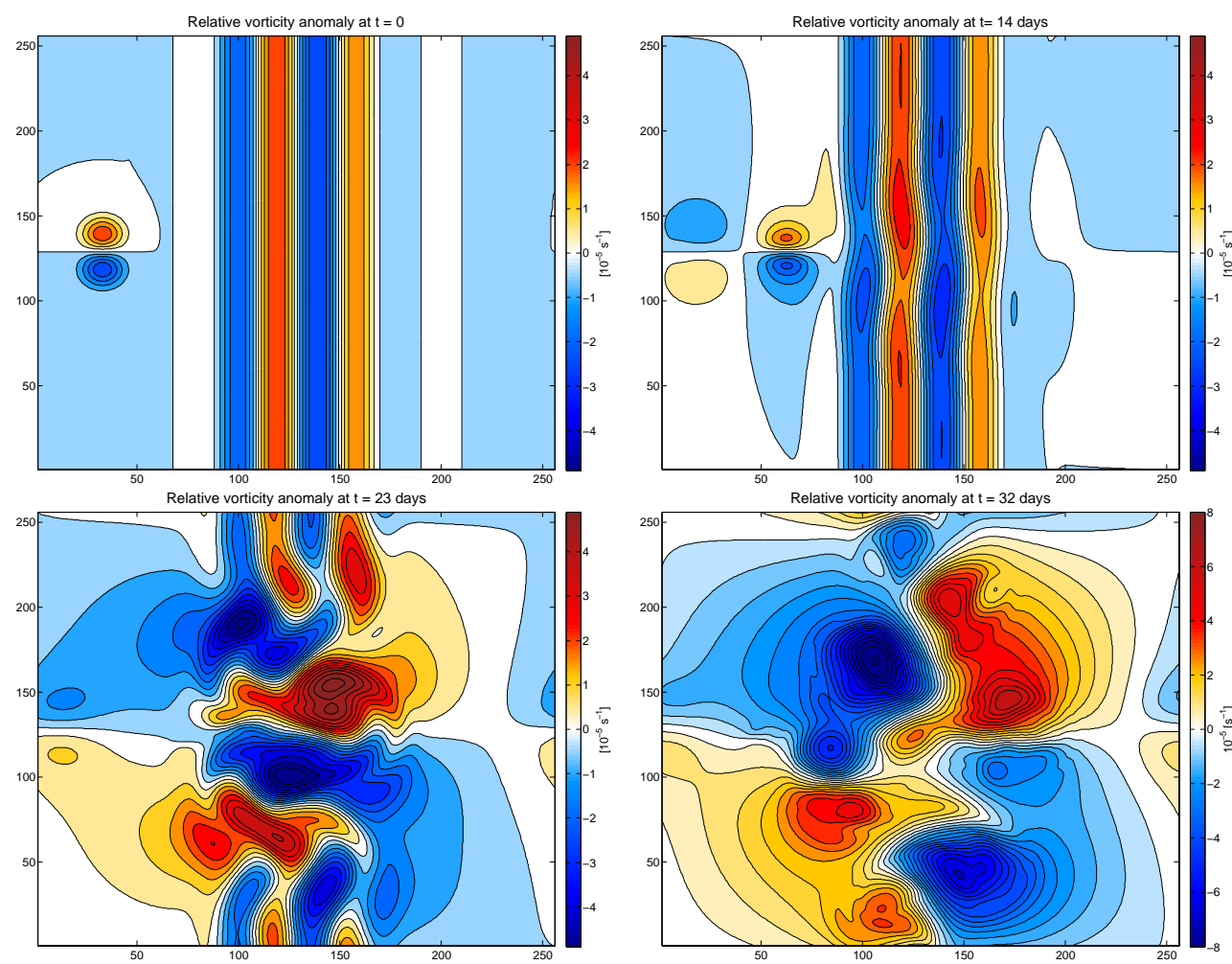

Figure 14. Evolution of the relative vorticity of a Rossby wave interacting with a dipolar eddy. 

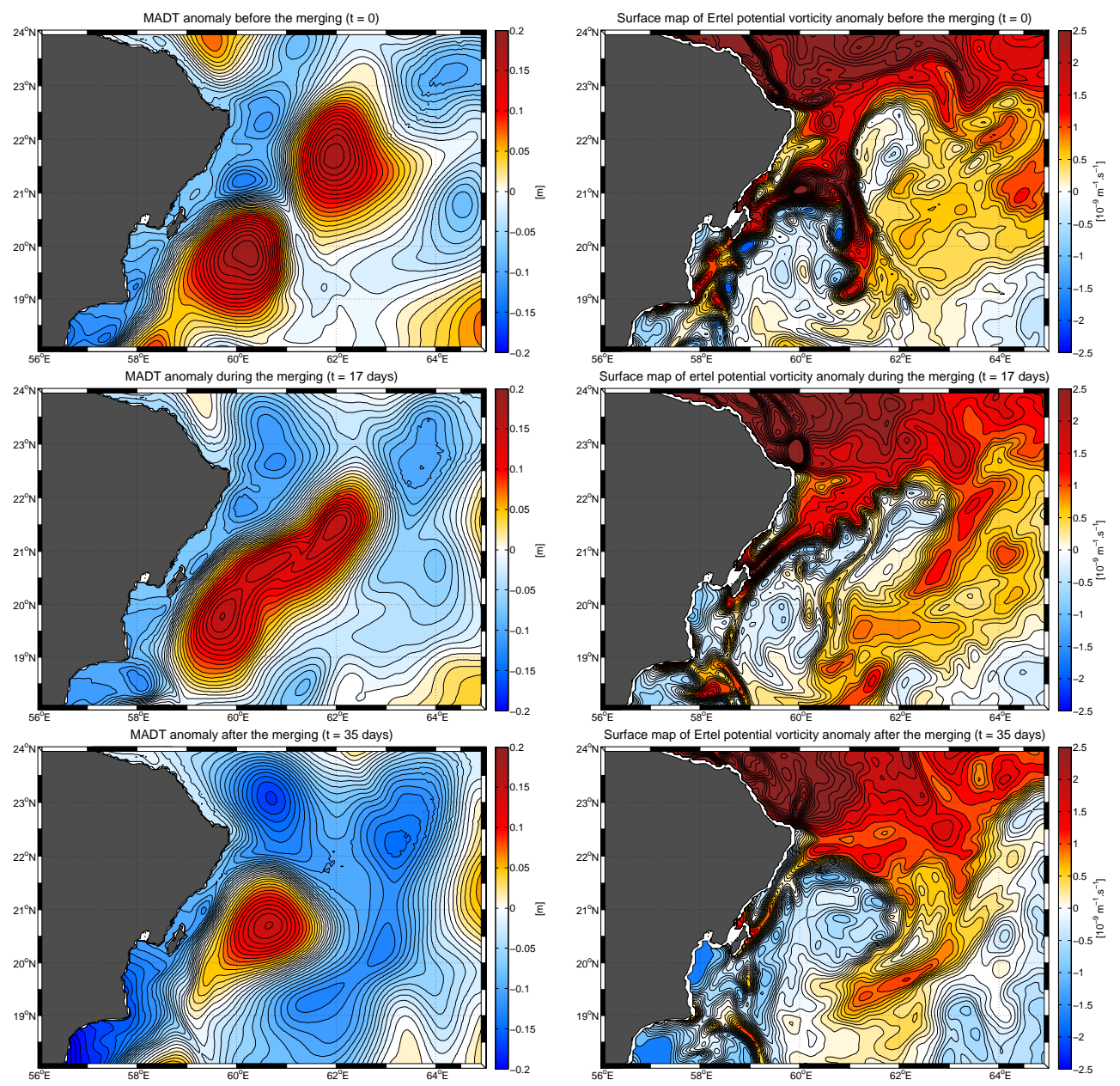

Figure 15. Evolution of the altimetry anomaly (left) and Ertel potential vorticity anomaly (right) during a merger of two anticyclones along the Oman Coastal Current for $t=0$ (top), $t=17$ days (center), and $t=35$ days (bottom). The Ertel potential vorticity anomaly field is strongly positive north of $22^{\circ} \mathrm{N}$ due to a strong front of density in summer.

The first term is related to the relative vorticity of the shear flow and the second to its divergence. In quasi-geostrophic flows the divergence term $\left\{K^{\prime} \bar{K}\right\}_{\nabla}$ is expected to be smaller than $\left\{K^{\prime} \bar{K}\right\}_{\xi}$ (see Haney et al., 2001). Five anticyclonic mesoscale eddies were followed in the HYCOM simulation, which stay at the same position and do not interact with other eddies. They had $\left\{K^{\prime} \bar{K}\right\}_{\xi}$ varying between about $2 \times 10^{-4}$ and $4 \times 10^{-3} \mathrm{~W} \mathrm{~m}^{-2}$, and $\left\{K^{\prime} \bar{K}\right\}_{\nabla}$ was about $7 \times 10^{-5}$ to $5 \times 10^{-4} \mathrm{~W} \mathrm{~m}^{-2}$; thus, there was a ratio of 2 to 8 between the transfer to the barotropic energy due to vorticity and the one due to divergence.

Figure 16 presents the evolution of the wind work, the transfer term from baroclinic to barotropic kinetic energy and the net heat flux compared to the tendency of the eddies' depth that followed during the spring intermonsoons.

For negative depth tendency (deepening of the eddies) the sum of wind work and $\left\{K^{\prime} \bar{K}\right\}_{\xi}$ is positive in tendency, mainly due to $P_{\text {down }}$. Other factors such as an eddy merger could occur, but the effect of the wind on the vertical signature of the eddy plays a noticeable role in the barotropization of the eddies. Also, during a deepening, the tendency of the net heat flux is positive, thus indicating a gain of temperature.

When the depth of the eddy remains constant $\left(\frac{\partial h}{\partial t} \approx 0\right)$, the term of barotropic energy transfer remains low.

For positive values of the depth tendency (shallowing of the eddies), both positive and negative values of the sum of barotropization terms are found. The strongest values are positive and principally due to the $\left\{K^{\prime} \bar{K}\right\}_{\xi}$ term. The net heat flux is negative in tendency for shallowing of the eddies (not shown), thus indicating a decreasing temperature.

\section{Evolution of the Persian Gulf Water in the Sea of Oman}

The Persian Gulf outflow enters a region of intense mesoscale dynamical activity. The outflow was earlier as- 

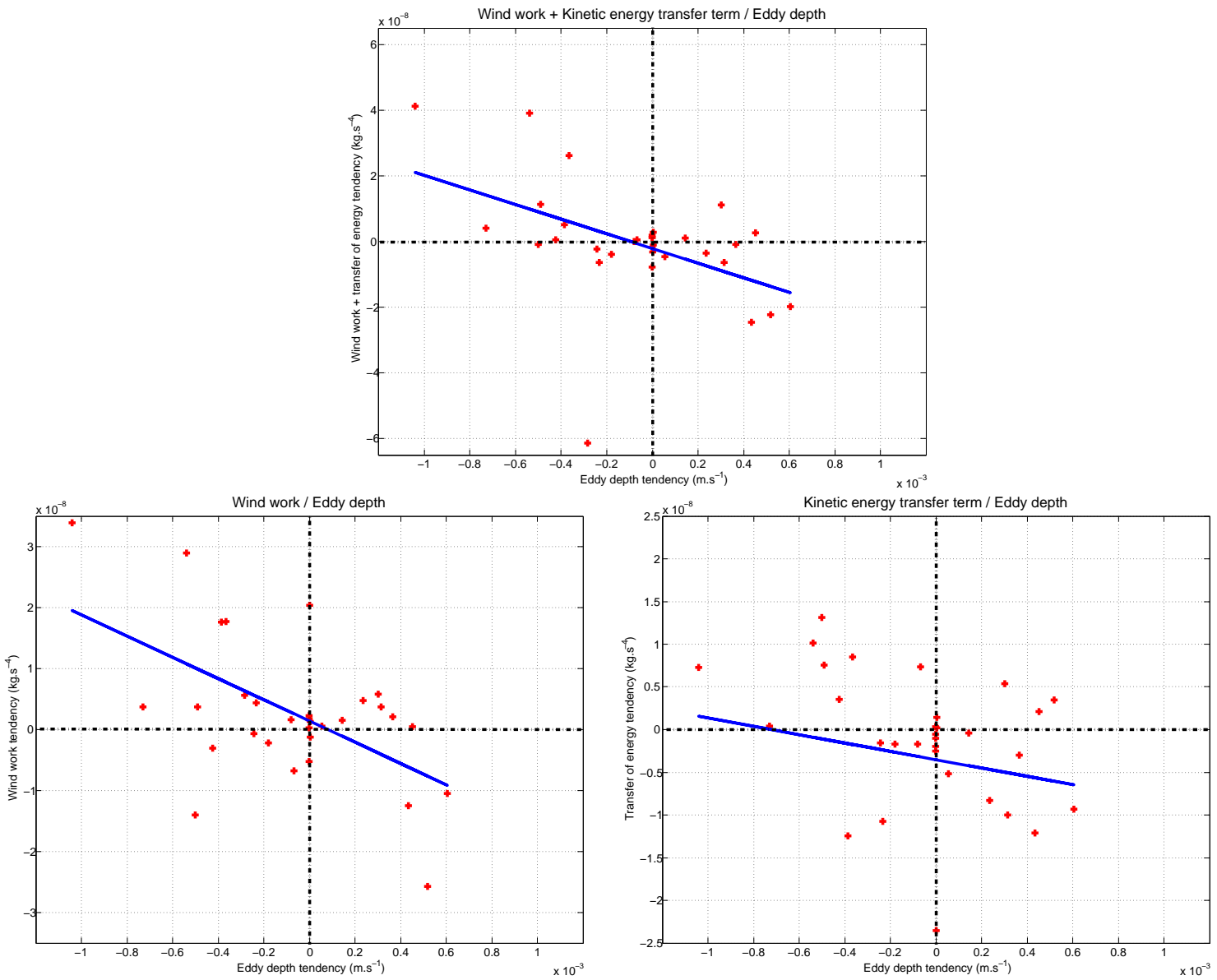

Figure 16. Comparison of the tendencies of transfer terms (energy and wind work) with the tendency of the eddies' depth. Five different stationary eddies were studied in the HYCOM simulation. The parameters are the wind work $P_{\text {down }}$ (bottom, left), the transfer term from the baroclinic energy to barotropic due to vorticity $\left\{K^{\prime} \bar{K}\right\}_{\xi}$ (bottom, right), and the sum of those two (top).

sumed to flow alongshore for most of the year; it was described as a coastal vein during the fall intermonsoon (see Pous et al., 2004b). This is consistent with the presence of the monsoonal coastal currents, but as observed in L'Hegaret et al. (2013), fragments of PGW can be found in the Sea of Oman, particularly during the spring intermonsoon under the influence of a dipole off Ra's Al Hamra. Fragments of PGW can also be found in the Arabian Sea (Carton et al., 2012). Using the HYCOM simulation, it is possible to study the evolution of the characteristics, pathway and dilution of the PGW. Four different mechanisms of ejection of the PGW observed in the simulation are presented hereafter. The thickness and width are estimated using the method of Pous et al. (2004b), the limit being the isohaline $\left(\frac{S_{\mathrm{PGW}}+S_{\mathrm{env}}}{2}\right)$, with $S_{\text {PGW }}$ the salinity of the PGW core and $S_{\text {env }}$ the salinity of the surrounding water mass. Also, transport of salt is calculated along the pathway of the outflow. This circulation corresponds to an Eulerian transport, across sections in the Sea of Oman at a specific period, during and after an ejection phenomenon. For each mechanism, the evolution of the MADT anomaly, the deformation field induced by the velocities, and the maximum of salinity at the PGW depth are presented.

\subsection{Coastal pulse and ejection off Ra's Al Hadd}

The focus here is on the evolution of the outflow between Ra's Al Hamra $\left(23.5^{\circ} \mathrm{N}, 58.5^{\circ} \mathrm{E}\right)$ and Ra's Al Hadd $\left(22.5^{\circ} \mathrm{N}, 59.8^{\circ} \mathrm{E}\right)$ (the PGW evolution in the western Sea of Oman will be discussed in a following subsection). For each year of the simulation, from the beginning of the summer monsoon until December, the outflow is observed to follow the coast of Oman. Nevertheless, short pulses of salt, with salinity anomalies larger than $0.5 \mathrm{psu}$, are observed two or three times each season for about 15 days (as seen in Fig. 17, left). The MADT anomaly reveals that these pulses are linked to the intensification of a cyclone near Ra's Al Hamra, thus increasing the outflow deformation in this region.

The pulse proceeds as follows: exiting from the strait, PGW is ejected near the Iranian coast, and wraps around an anticyclone located near the Strait of Hormuz; then PGW heads southwards towards the Omani coast as a jet accom- 
panied by a dipole. The western anticyclone of this dipole remains trapped under the surface anticyclone while the eastern PGW cyclone is elongated along the Omani coast under the influence of the surface cyclone there. This leads to a coastal pulse along the Omani coast between Ra's Al Hamra and Ra's Al Hadd and to its ejection at Ra's Al Hadd.

Figure 18 presents the characteristics of the PGW during and after the pulse. In the left-hand panel, the pulse is associated with an abrupt change in the depth of the outflow and thickness of more than $50 \mathrm{~m}$ near kilometers 700 to 900 . The salinity above 37.2 psu decreases southeastward at the front of the pulse to the surrounding water salinity, below $36.5 \mathrm{psu}$. The salt transport is over $2.5 \times 10^{8} \mathrm{~kg} \mathrm{~s}^{-1}$ in the eastern part of the pulse, associated with the strongest velocities. West of the pulse, between kilometers 600 and 700, the outflow recirculates cyclonically, being shallower (near $150 \mathrm{~m}$ ) and with a thickness of $130 \mathrm{~m}$. The salinity of this cyclone is the same as the pulse and has a salt transport of $1.3 \times 10^{8} \mathrm{~kg} \mathrm{~s}^{-1}$.

After the pulse, the outflow remains at a depth of $190 \mathrm{~m}$, whereas its thickness decreases from 140 to $110 \mathrm{~m}$. Furthermore, the flow follows the coast, keeping a constant and thin width of $30 \mathrm{~km}$. The salinity also decreases along the coast by $0.1 \mathrm{psu}$ over $200 \mathrm{~km}$. The salt transport is above $10^{8} \mathrm{~kg} \mathrm{~s}^{-1}$, up to $3 \times 10^{8} \mathrm{~kg} \mathrm{~s}^{-1}$, strongly depending on the velocities. It then forms a narrow and intense coastal jet.

Offshore from Ra's Al Hadd, the PGW is ejected in summer under the influence of a dipole, the Ra's Al Hadd jet, clearly marked on the deformation map (see Fig. 18). The outflow then wraps around the mesoscale eddies, supplying them with salt, bringing a salinity above 36.9 psu in their core. The filaments at their periphery disappear within a month, being subject to strong mixing. On the map from 21 August, the filament near Ra's Al Hadd recirculates to form a submesoscale structure. This filament formation is observed from the summer monsoon to the fall intermonsoon at a time when the Ra's Al Hadd jet disappears.

\subsection{Formation of a lee eddy}

In winter, the PGW outflow is known to veer southwestward around Ra's Al Hadd. In the HYCOM model, $75 \%$ of the simulated years presented the formation of an anticyclonic lee eddy downstream of Ra's Al Hamra, during the early winter monsoon (for lee eddies, see Verron et al., 1991). This formation is related to a strong deformation field around Ra's Al Hamra (see Fig. 19); the outflow is squeezed toward the coast, recirculating in an anticyclonic eddy with a positive MADT anomaly.

Figure 20 (left) shows the characteristics of the PGW during the formation of the lee eddy between 450 and $650 \mathrm{~km}$. The flow becomes wider, about $75 \mathrm{~km}$ thicker, to about $180 \mathrm{~m}$, and shallower, with a maximal salinity at $180 \mathrm{~m}$ depth. The salinity of the structure does not change from the surrounding water, about $37.2 \mathrm{psu}$, but the outflow then corresponds to a larger salt transport (about $1.5 \times 10^{8} \mathrm{~kg} \mathrm{~s}^{-1}$ in the interior of the forming lee eddy). East of it, between the 700 and $800 \mathrm{~km}$ marks, a filament of PGW is observed, having a large transport, a depth around $180 \mathrm{~m}$ and a thickness decreasing by $75 \mathrm{~m}$ over $100 \mathrm{~km}$, corresponding to a dilution of 0.2 psu in $100 \mathrm{~km}$.

In the right-hand panel of Fig. 20, the characteristics of the ejected lee eddy and of the filament linking it to the coast are observable downstream of kilometer 750, and the lee eddy is found after the $1000 \mathrm{~km}$ position, 3 weeks after its formation. Between the coast and the eddy, the PGW structure is highly variable, beginning with a shallower depth (from 220 to $170 \mathrm{~m}$ ) and smaller thickness (from 140 to $120 \mathrm{~m}$ ), as a consequence of a strong and variable deformation field; the outflow is fragmented in filaments. Nevertheless, it keeps a constant salinity at $36.9 \mathrm{psu}$ and a high transport of salt up to $2 \times 10^{8} \mathrm{~kg} \mathrm{~s}^{-1}$. The lee eddy has stronger anomaly, a salinity around $37 \mathrm{psu}$, and a salt transport above $3 \times 10^{8} \mathrm{~kg} \mathrm{~s}^{-1}$. It also has a size comparable to the eddy formed via the deformation of the coastal current with a width of $150 \mathrm{~km}$, a thickness larger than $200 \mathrm{~m}$, and a depth of $180 \mathrm{~m}$.

This structure remains coherent for several months, from December through March, drifting towards the Indian Ocean, slowly eroding, losing about 0.1 psu per month. This is the only feature observed in the model capable of advecting high salinity PGW in the Arabian Sea without being quickly diluted.

\subsection{Ejection of PGW via a dipole}

In spring, the monsoonal winds have a weak intensity, and no coastal surface current is observed in the Sea of Oman. As observed in L'Hegaret et al. (2013), a mesoscale eddy dipole can be found in the basin, with an intense anticyclone east of Ra's Al Hamra and a cyclonic feature west. This dipole is observed in $50 \%$ of the HYCOM simulation results. In the other years, the anticyclone is observed to the west. In Fig. 21, the anticyclone is inducing deformation along the coast (between Ra's Al Hamra and Ra's Al Hadd) and at the center of the basin, advecting the PGW in an anticyclonic motion.

From kilometer 600 on, in Fig. 22 (left), the ejection induces variations of the depth and width of PGW near the coast. The PGW outflow rises and widens before ejection and then equilibrates around $200 \mathrm{~m}$ depth and $50 \mathrm{~km}$ width, with a salinity of $37.2 \mathrm{psu}$. Also, the salt transport increases along the coast, up to $2 \times 10^{8} \mathrm{~kg} \mathrm{~s}^{-1}$, but is weaker, around $0.5 \times 10^{8} \mathrm{~kg} \mathrm{~s}^{-1}$, in the ejection. The front of the filaments, between kilometers 900 and 1100 , presents a difference of $0.6 \mathrm{psu}$ in $100 \mathrm{~km}$ and an abrupt change in depth and thickness.

Two weeks later (see Fig. 22, right), from kilometers 400 to 700, a second PGW ejection at Ra's Al Hamra occurs: its transport of PGW is above $2.5 \times 10^{8} \mathrm{~kg} \mathrm{~s}^{-1}$. Nevertheless, the front of this ejection does not reach the coast, as it is occupied by the remaining filament of the previous ejection. 

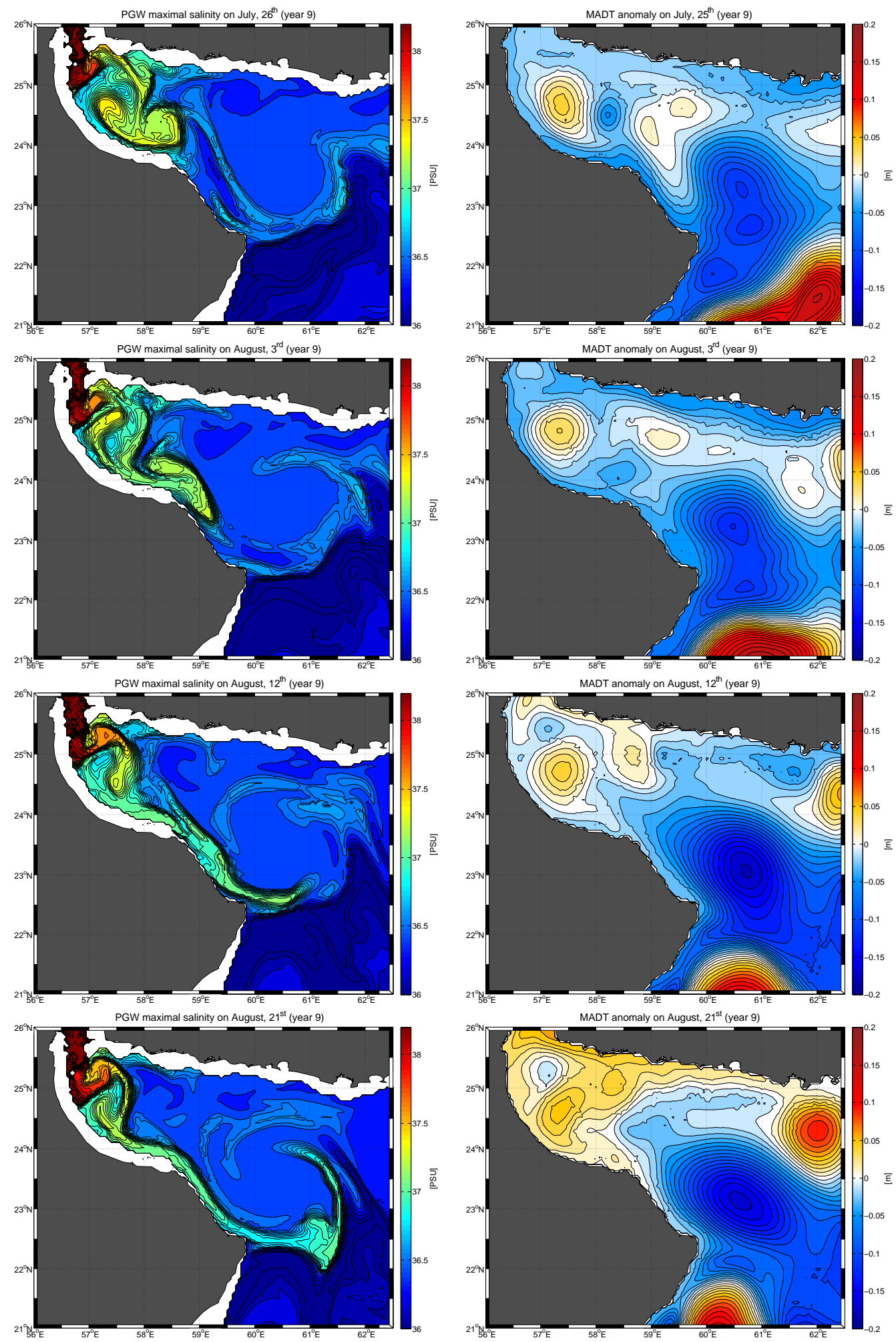

Figure 17. Evolution of the maximal PGW salinity (left) and MADT anomaly (right) during a pulse of PGW and an ejection of PGW at Ra's Al Hadd in year 9 of the HYCOM simulation, on 25 July (first row), 3 August (second row), 12 August (third row) and 21 August (fourth row). 

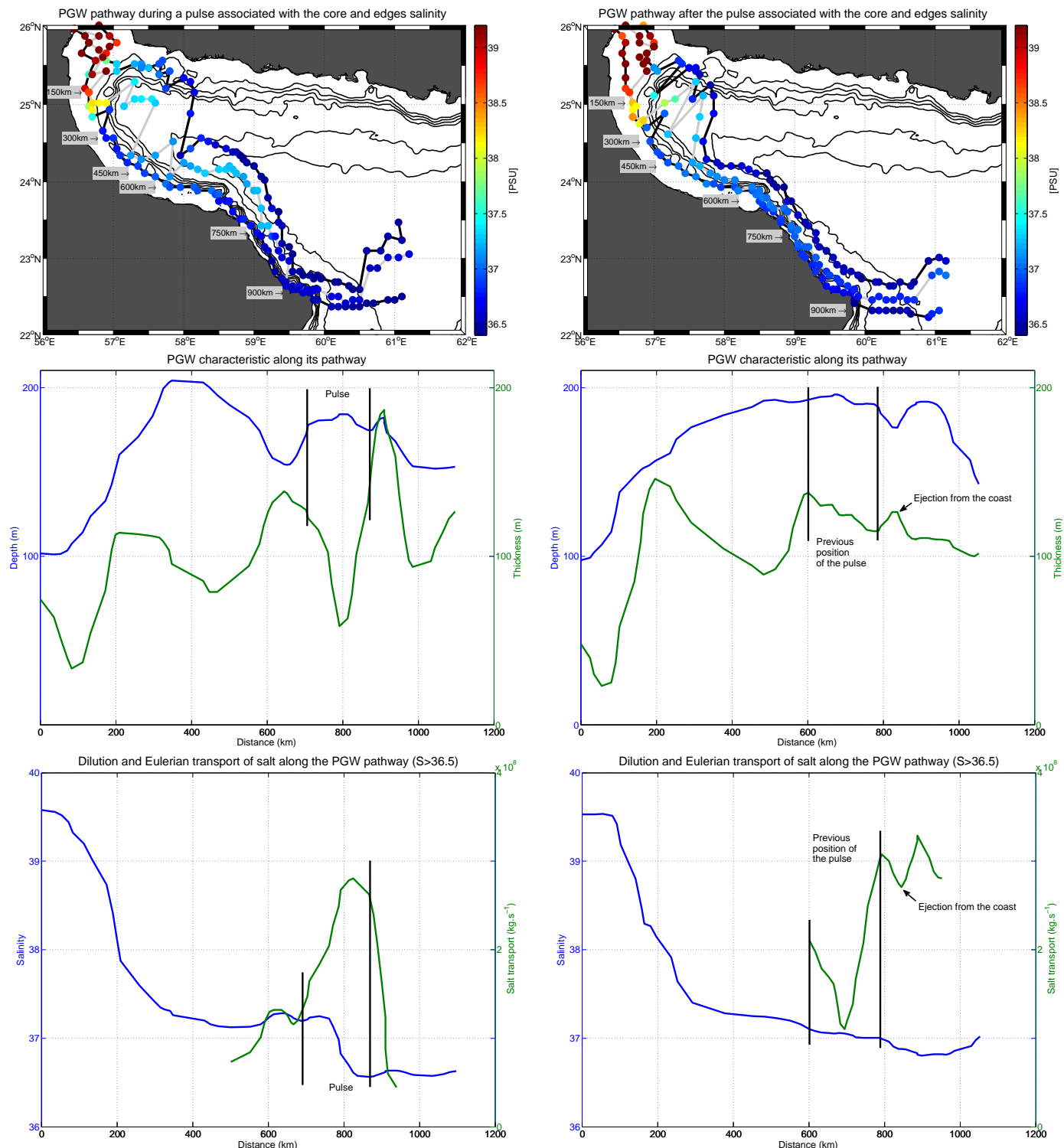

Figure 18. Evolution of the PGW characteristics during the pulse (on 3 August, left) and after the pulse (on 21 August, right). The first row shows the pathway of the maximal salinity of PGW and the width of the outflow. The second row displays the depth and thickness of the outflow and the third row maximal salinity and transport of salt along the downstream bathymetry.

Inside the Sea of Oman, after the $700 \mathrm{~km}$ mark, the PGW outflow keeps a steady depth of $210 \mathrm{~m}$, a $50 \mathrm{~km}$ width and a thickness quickly dropping from 170 to $60 \mathrm{~m}$. The salt transport is low, with $0.5 \times 10^{8} \mathrm{~kg} \mathrm{~s}^{-1}$, and the PGW vein loses salinity at a rate of about 0.1 psu per week and every $100 \mathrm{~km}$.

Several ejections can occur each spring, similar to the mushroom-like pattern that can be observed on the map of 12 June (Fig. 21). This pattern is associated with recirculations of PGW, part of it being advected eastward, out of the Sea of Oman, whereas another branch veers westward. It is then possible to have, at the same location, two PGW masses with different characteristics, a newer, denser one presenting high salinity, and an older, lighter one that has been subject to dilution and thus presents a lower salinity.

\subsection{Ejection of PGW along the northern coast near the Strait of Hormuz}

In the western Sea of Oman, an ejection of PGW is also observed under the influence of an anticyclonic eddy (see Fig. 23). Directly off Hormuz, the outflow, instead of following the southern coast, is advected northward. The anticyclone induces high deformation of the flow.

Between kilometers 150 and 300 (Fig. 24), the outflow follows the coast, with a depth of $240 \mathrm{~m}$ and a salinity of $38 \mathrm{psu}$ 

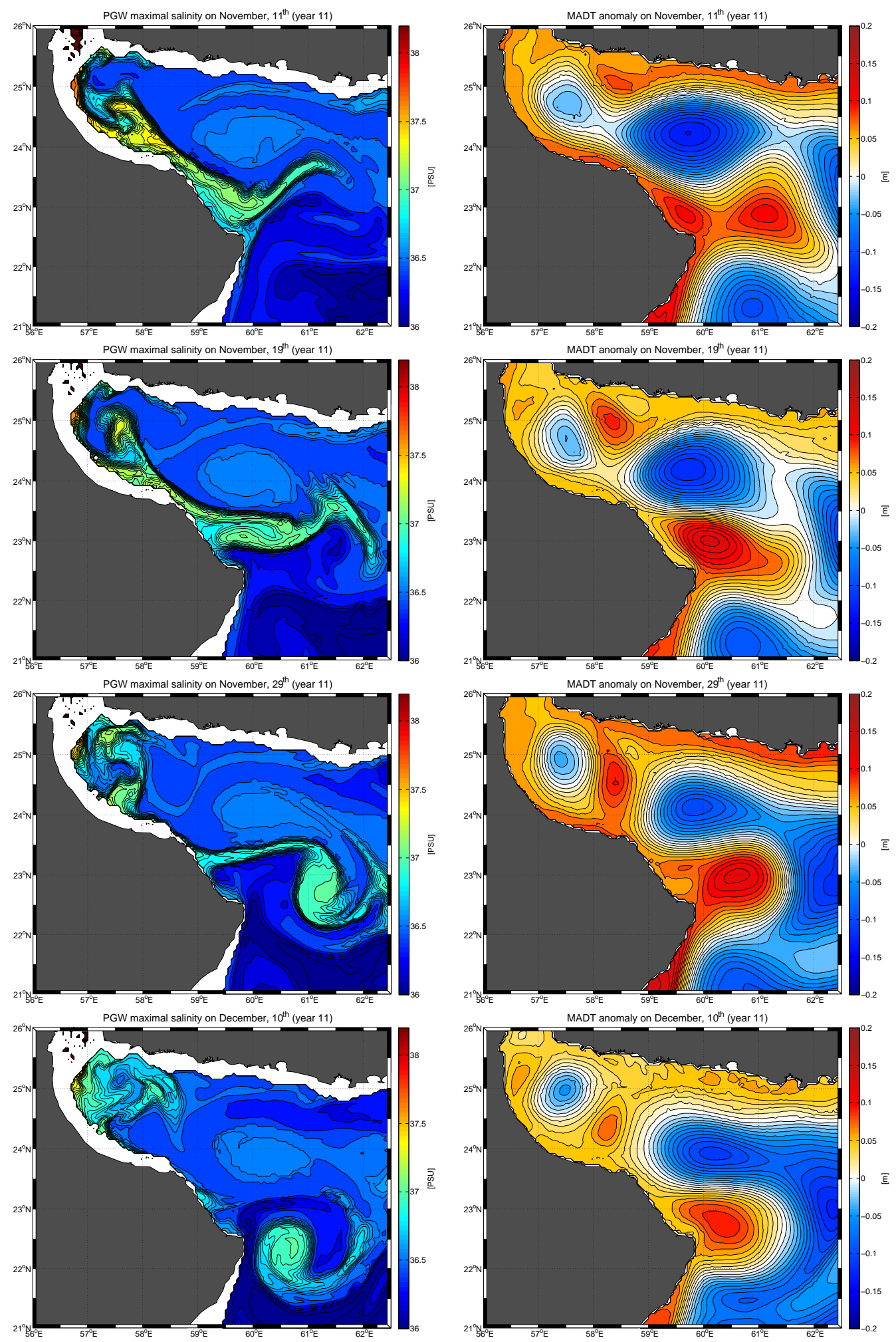

Figure 19. Evolution of the maximal PGW salinity (left) and MADT anomaly (right) during the formation of a lee eddy in year 11 of the HYCOM simulation, on 11 November (first row), 19 November (second row), 29 November (third row) and 10 December (fourth row). 

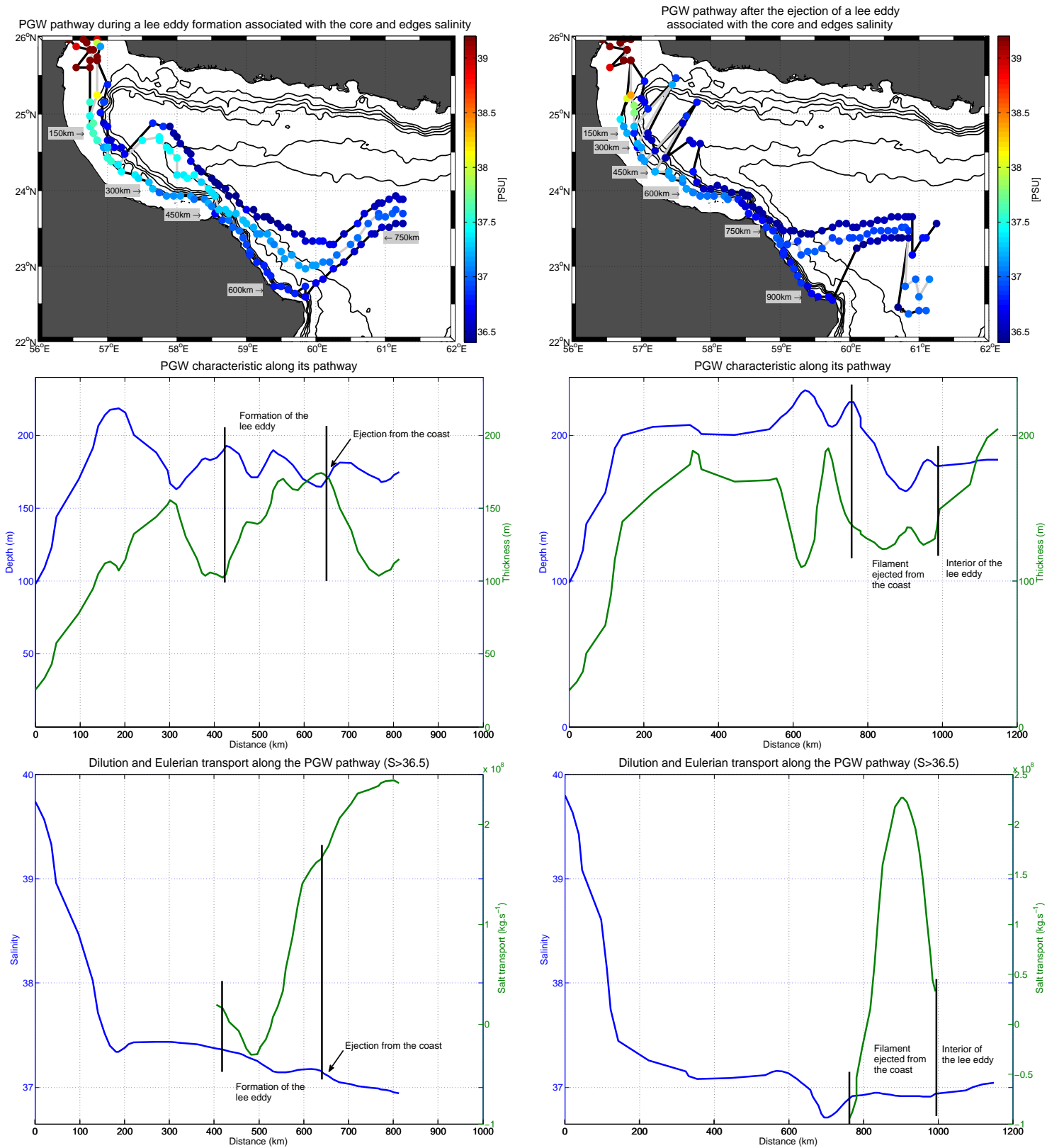

Figure 20. Evolution of the PGW characteristics during the formation of a lee eddy (on 11 November, left) and after its ejection from the coast (on 29 November, right). The first row shows the pathway of the maximal salinity of PGW and the width of the outflow. The second row displays the depth and thickness of the outflow and the third row maximal salinity and transport of salt along the downstream bathymetry.

when reaching the northern coast. Then, the transport of the salt maximal value, near $1.3 \times 10^{8} \mathrm{~kg} \mathrm{~s}^{-1}$, is found at kilometer 250 , associated with a deepening and a thickening of the outflow, probably due to an anticyclonic structure observed on the MADT map. After $400 \mathrm{~km}$, this transport becomes negative, due to a convergence of the northern waters. The outflow is ejected from the coast, shallowing to $190 \mathrm{~m}$ and with a salinity above 37.4 psu. As for the ejection by a dipole, the front of the ejection presents an important change in salt, near kilometer 550 .
The southward ejection reaches the Omani coast with a mushroom-like form, yielding one branch exiting the Sea of Oman, and another one recirculating in the Sea of Oman. A branch of the outflow then wraps around a cyclonic eddy. In the right-hand panel of Fig. 24, from kilometers 420 to 600 , the salinity remains constant inside this eddy, around 36.3. Between 200 and $400 \mathrm{~km}$, the coastal outflow keeps providing saline water, with a positive transport of salt around $10^{8} \mathrm{~kg} \mathrm{~s}^{-1}$ 

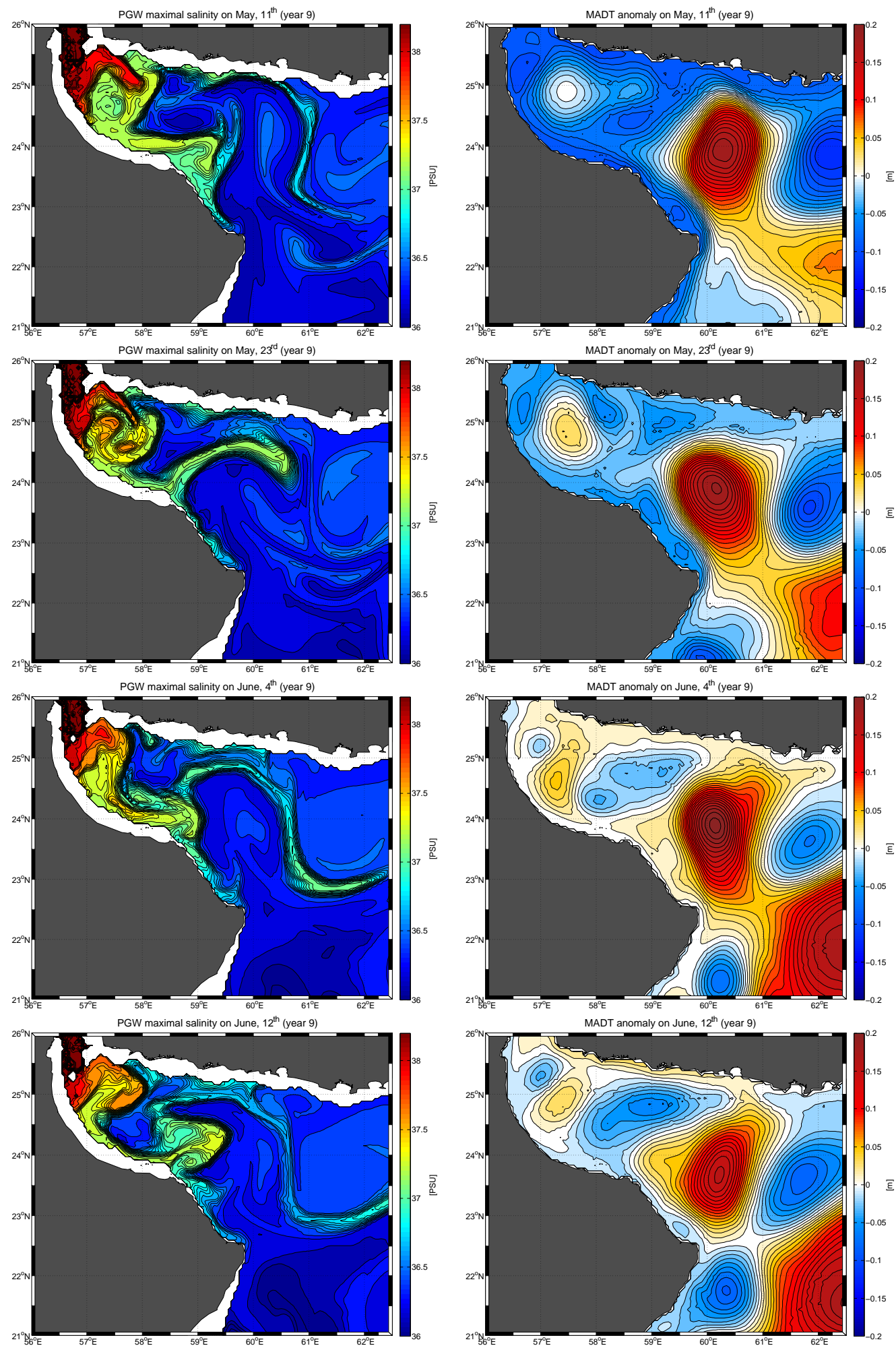

Figure 21. Evolution of the maximal PGW salinity (left) and MADT anomaly (right) during an ejection of PGW off Ra's Al Hamra in year 9 of the HYCOM simulation, on 11 May (first row), 23 May (second row), 4 June (third row) and 12 June (fourth row). 

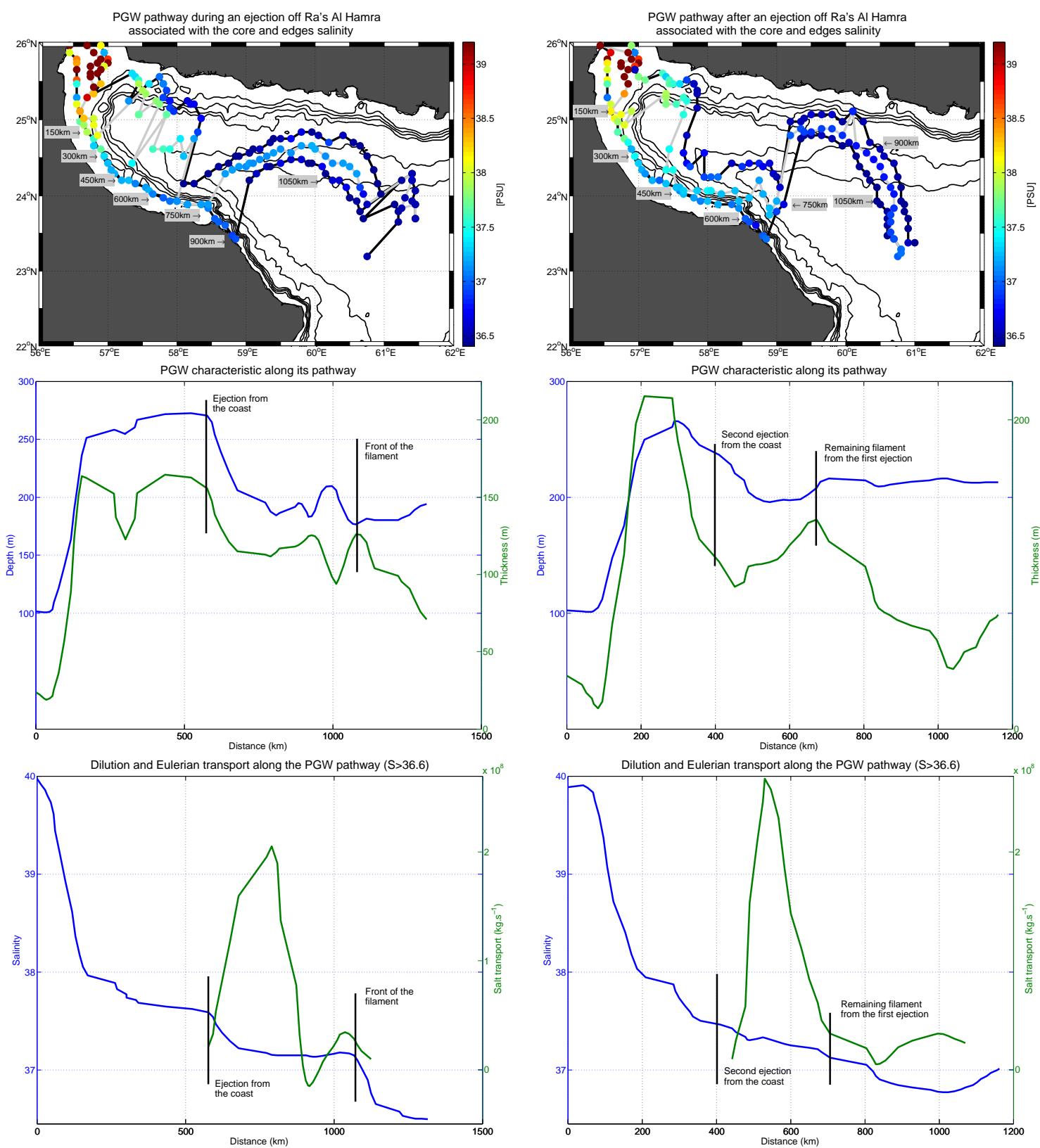

Figure 22. Evolution of the PGW characteristics during the ejection off Ra's Al Hamra (on 23 May, left) and after (on 4 June, right). The first row shows the pathway of the maximal salinity of PGW and the width of the outflow. The second row displays the depth and thickness of the outflow and the third row maximal salinity and transport of salt along the downstream.

This ejection mechanism is observed primarily during the winter monsoon, with the coastal current advecting the outflowing water northward, but it is also observed in spring and summer, in the presence of an anticyclonic eddy. Finally, this mechanism is not observed in the HYCOM simulation during the fall intermonsoon, where the circulation in the Sea of Oman is dominated by an intense cyclonic eddy.

\subsection{Salt transport from Hormuz to the Sea of Oman}

In the previous panels, for each ejection mechanism, important changes occur in PGW in the first $100-150 \mathrm{~km}$ downstream of Hormuz. Exiting the Persian Gulf, at Hormuz, the PGW has salinity between 39.5 and 40, and flows as a bottom current, at $100 \mathrm{~m}$ depth and with a width of about $50 \mathrm{~km}$, with an associated salt transport of about $10^{8} \mathrm{~kg} \mathrm{~s}^{-1}$. At shelf break the flow cascades down on the continental slope and turbulent mixing occurs with the surrounding water, either 

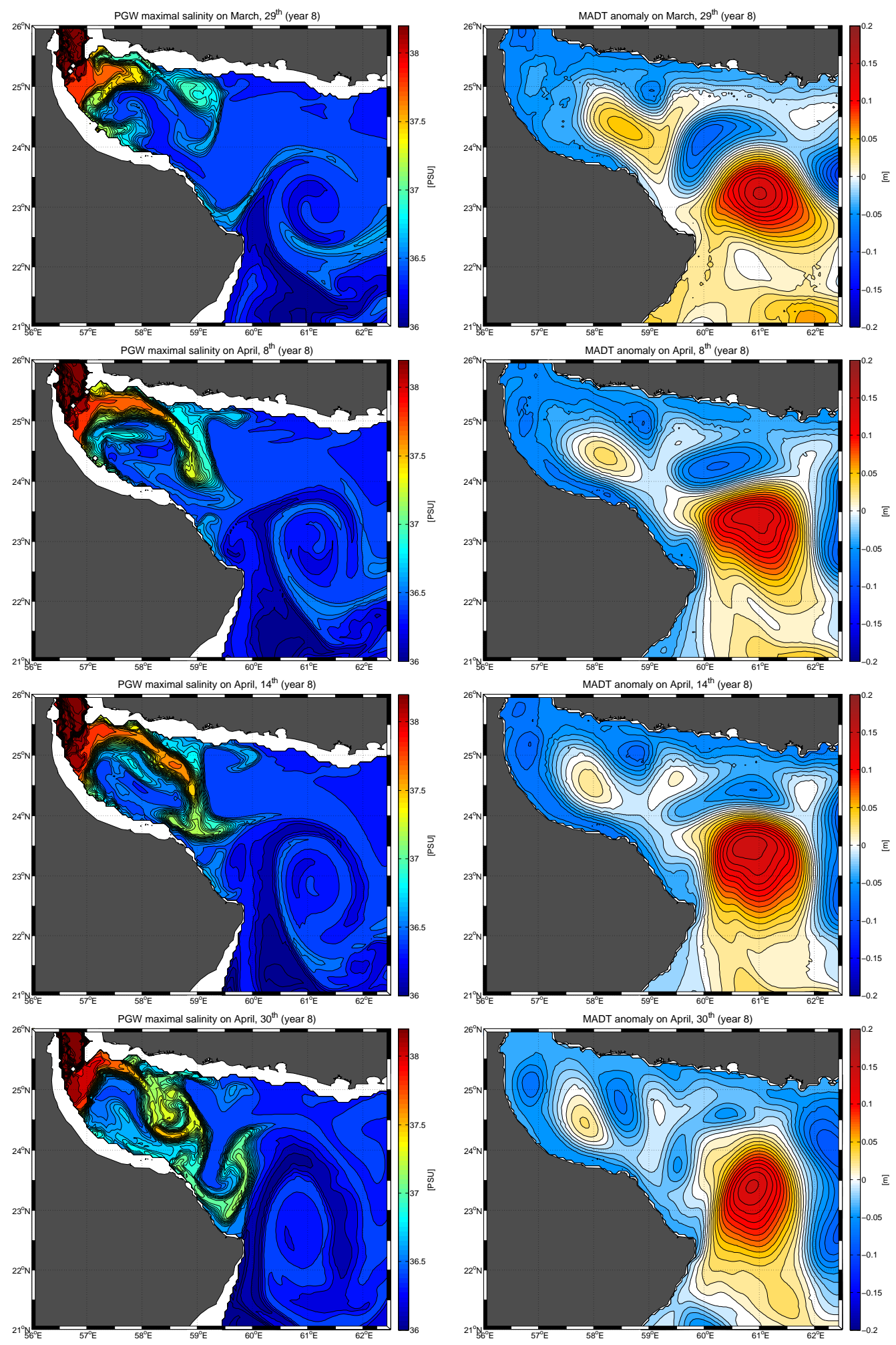

Figure 23. Evolution of the maximal PGW salinity (left) and MADT anomaly (right) during an ejection along the northern coast of the Sea of Oman in year 9 of the HYCOM simulation, on 29 March (first row), 8 April (second row), 14 April (third row) and 30 April (fourth row). 

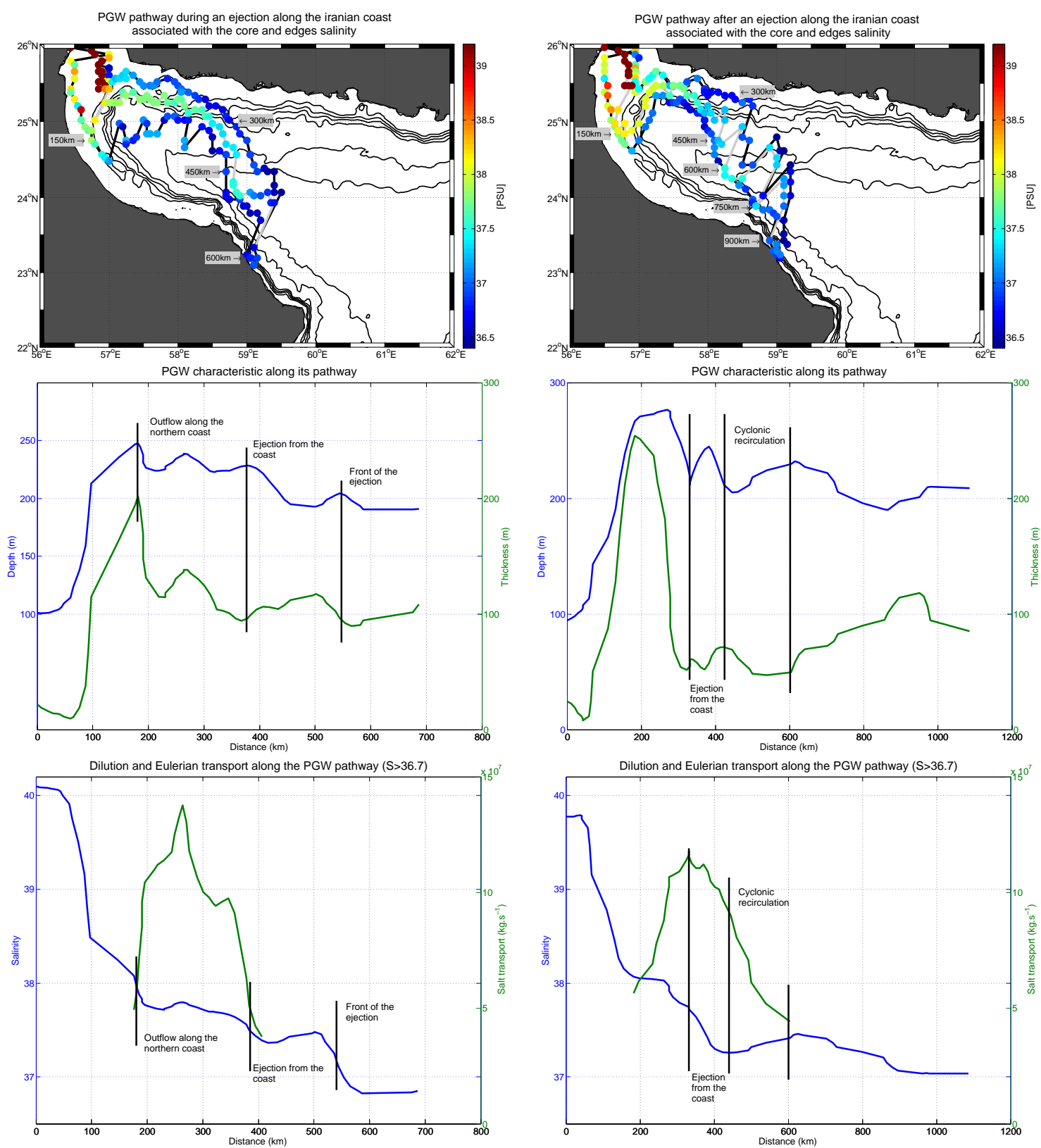

Figure 24. Evolution of the PGW characteristics during the ejection from the northern coast (on 8 April, left) and after (on 30 April, right). The first row shows the pathway of the maximal salinity of PGW and the width of the outflow. The second row displays the depth and thickness of the outflow and the third row maximal salinity and transport of salt along the downstream.

IOCW or diluted PGW. The outflow deepens below $200 \mathrm{~m}$ and widens around $100 \mathrm{~km}$. As a result of the mixing, during the cascading downslope the salinity of the outflow drops to 38 psu by 2 psu in less than $100 \mathrm{~km}$.

Then the PGW flows along the southern coast, or is advected northward, and can recirculate in this western region. The outflow maintains a salinity between 37.2 and $38 \mathrm{psu}$, and sinks around $250 \mathrm{~m}$. The thickness and width often reached large values (over $150 \mathrm{~m}$ and $100 \mathrm{~km}$ ) due to the recirculation and to the presence of PGW from different seasons.

Downstream in the Sea of Oman, PGW loses $0.1 \mathrm{psu}$ every $100 \mathrm{~km}$; ejection via dipoles or pulses contributes to temporarily halt the dilution, but PGW is then diluted at the periphery of the eddy. When PGW reaches the core of the eddies, the salinity in these cores increases by $0.3 \mathrm{psu}$, and up to $0.8 \mathrm{psu}$ for the lee eddy. 


\section{Conclusions}

In this study the mesoscale activity in the Arabian Sea and Sea of Oman was assessed by using HYCOM model outputs, measurements from satellites, floats and climatology. Notable similarities were found in the water mass thermohaline characteristics and altimetric signatures between model and data. The surface circulation is highly seasonal under the influence of the wind stress, creating strips of MADT anomaly along the coasts, positive in winter, negative in summer, with branches along the Arabian Peninsula forming the Omani Coastal Current. This surface current deforms to form mesoscale eddies propagating westward with a vertical influence extending below $1000 \mathrm{~m}$ depth. Along the coast of India, Rossby waves are radiated under the influence of coastal Kelvin waves, or of wind stress. These Rossby waves have been observed, and in simulation have been found to destabilize and to transform into eddies under the influence of the topography. They can then interact with mesoscale dipoles near the coast of Oman.

The mesoscale eddies interact in different ways across the basin. Two close eddies with the same polarity can merge to form a larger structure; nevertheless, near the coastal current, the final eddy often has a size similar to the earlier ones. Two eddies with opposite polarity advect each other as dipoles. Strong wind favors the deepening and barotropization of the eddies. The net heat fluxes also showed a gain or loss of heat with the deepening or shallowing of the eddies' depth.
The Persian Gulf outflow is impacted by the mesoscale eddies, influencing its pathway along the Sea of Oman; PGW ejection from the coast occurs, from the Ra's Al Hadd cape in summer, from Ra's Al Hamra in spring and fall, and along the northern coast in winter. The thermohaline characteristics are also changed by recirculation in the western part of the basin, by the generation of eddies or by the breaking of the core, these phenomena leading to thermohaline mixing. The injection of PGW inside eddies allows this water mass to keep a stronger thermohaline signature across the Arabian Sea, filaments being more subject to erosion, whereas other structures, such as lee eddies in winter, keep higher salinity for several months. Note that the salinity of PGW decreases mostly in the first $150 \mathrm{~km}$ from the Strait of Hormuz as a consequence of cascading or of entrainment on the bottom slope.

Thus, this study provides a description of the path of PGW outflow from its exit from the Strait of Hormuz to its dispersion in the Arabian Sea. Several types of mesoscale eddies containing PGW (lee eddies, isolated eddies, dipoles) were found, as well as filaments. Further investigation of these submesoscale structures using in situ data of the Phys-Indien experiments, and the analysis of fine-scale intrusions at thermohaline fronts, will be the subject of a forthcoming paper. 


\section{Appendix A: Interaction of a long Rossby wave with a circular seamount}

In this section, we provide a simple analytical calculation for the interaction of a long, zonal Rossby wave with a localized, circular (parabolic-shaped) seamount. We use the two-dimensional or barotropic vorticity equation on the beta plane with bottom topography:

$\partial_{t}\left(\nabla^{2} \psi\right)+J\left(\psi, \nabla^{2} \psi\right)+J\left(\psi, f_{0} h_{b} / H\right)+\beta \partial_{x} \psi=0$.

Our basic flow is a zonal Rossby wave with wave number $k$ $\psi_{0}(x, t)=A_{0} \exp (i k[x-c t])=A_{0} \exp (i k[r \cos (\theta)-c t])$,

which is a solution of the nonlinear vorticity equation over a flat bottom with $c=\frac{-\beta}{k^{2}}$. We also recall that

$\nabla^{2} \psi_{0}=-k^{2} \psi_{0}$

Furthermore, we assume that the seamount height is small, $f_{0} h_{b} / H=\epsilon A_{b}(r)$, and that it has a radius $r_{0} \ll 2 \pi / k$.

Since the topographic term is small in the vorticity equation, we can look for a response of the flow in terms of a perturbation expansion

$\psi(x, y, t)=\psi_{0}(x, t)+\epsilon \psi_{1}(x, y, t)$.

Thus we have, at order $\epsilon$,

$$
\begin{aligned}
& \partial_{t}\left(\nabla^{2} \psi_{1}\right)+J\left(\psi_{0}, \nabla^{2} \psi_{1}\right)+J\left(\psi_{1}, \nabla^{2} \psi_{0}\right)+\beta \partial_{x} \psi_{1} \\
& \quad+J\left(\psi_{0}, A_{b}\right)=0 .
\end{aligned}
$$

To simplify this equation further, we assume that $A_{b}=$ $A_{b}^{0}\left(1-\left(r / r_{0}\right)^{2}\right)$, so that the last term is simply

$\left(2 A_{b}^{0} / r_{0}^{2}\right) \partial_{\theta} \psi_{0}=-2 i k r \sin (\theta)\left(A_{0} A_{b}^{0} / r_{0}^{2}\right) \exp (i k[x-c t])$,

or, more simply, a term in $y \exp (i k[x-c t])$ that is going to force the flow response in $\psi_{1}$. Thus we assume that

$\psi_{1}=\phi_{1} y t \exp (i k[x-c t])$.

Then,

$\nabla^{2} \psi_{1}=-k^{2} \phi_{1} y t \exp (i k[x-c t])=-k^{2} \psi_{1}$

Therefore, the vorticity anomaly over the seamount is

$J\left(\psi_{0}, \nabla^{2} \psi_{1}\right)+J\left(\psi_{1}, \nabla^{2} \psi_{0}\right)=0$.

Now

$\partial_{t}\left(\nabla^{2} \psi_{1}\right)=(1-i k c t)\left(-k^{2}\right) \phi_{1} y \exp (i k[x-c t])$

and

$\beta \partial_{x} \psi_{1}=i k \beta \phi_{1} y t \exp (i k[x-c t])$, which cancels out the second term of the time derivative. Therefore

$-k^{2} \phi_{1} y \exp (i k[x-c t])-2 i k y\left(A_{0} A_{b}^{0} / r_{0}^{2}\right) \exp (i k[x-c t])=0$

or finally

$\phi_{1}=-2 i A_{0} A_{b}^{0} /\left(k r_{0}^{2}\right)$.

The velocity associated with the zonal Rossby wave is meridional $v_{0}=\partial_{x} \psi_{0}=i k A_{0} \exp (i k[x-c t])$. Therefore

$\nabla^{2} \psi_{1}=2 A_{b}^{0} y t \quad v_{0} / r_{0}^{2}$.

From this, one can see immediately that negative vorticity will be created by a northward motion of the particles $\left(v_{0}>0\right)$ on the southern side of the seamount $(y<0$, where the fluid columns will experience squeezing) and conversely on the northern side of the seamount. If the wavelength of the Rossby wave is long compared with the radius of the seamount, enough perturbation vorticity will build up on these two sides of the mount and a dipole will be formed that can then detach. 
Acknowledgements. The authors are grateful to Gilles Reverdin, Fabien Durand, the two referees and Matthew Hecht whose suggestions and remarks greatly improved the contents of this paper. This work was supported by DGA under the SYNBIOS project.

Edited by: M. Hecht

\section{References}

Bower, A. S., Hunt, H. D., and Price, J. F.: Character and dynamics of the red Sea and the Persian Gulf outflows, J. Geophys. Res.Oceans, 105, 6387-6414, 2000.

Carnes, M. R.: Description and Evaluation of GDEM-V 3.0, Naval Research Lab Stennis Space Center Ms Oceanography Div, 2009.

Carton, X., L'Hegaret, P., and Baraille, R.: Mesoscale variability of water masses in the Arabian Sea as revealed by ARGO floats, Ocean Sci., 8, 227-248, doi:10.5194/os-8-227-2012, 2012.

Chassignet, E. P., Hurlburt, H. E., Smedstad, O. M., Halliwell, G. R., Hogan, P. J., Wallcraft, A. J., Baraille, R., and Bleck, R.: The HYCOM (HYbrid Coordinate Ocean Model) data assimilative system, J. Marine Syst., 65, 60-83, 2007.

Couder, Y. and Basdevant, C.: Experimental and numerical study of vortex couples in two-dimensional flows, J. Fluid Mech., 173, 225-251, 1986.

Defant, A.: Physical Oceanography, Pergamon Press, 2, 598 pp., 1961.

Dong, C., McWilliams, J. C., and Shchepetkin, A. F.: Island wakes in deep water, J. Phys. Oceanogr., 37, 962-981, 2007.

Flagg, C. N. and Kim, H.-S.: Upper ocean currents in the northern Arabian Sea from shipboard ADCP measurements collected during the 1994-1996 US JGOFS and ONR programs, Deep-Sea Res. Pt. II, 45, 1917-1959, 1998.

Flierl, G. R., Carton, X. J., and Messager, C.: Vortex formation by unstable oceanic jets, European Series in Applied and Industrial Mathematics: Proceedings, 7, 137-150, 1999.

$\mathrm{Fu}, \mathrm{L}$.-L.: Intraseasonal variability of the equatorial Indian Ocean observed from sea surface height, wind, and temperature data, J. Phys. Oceanogr., 37, 188-202, 2007.

Fu, L.-L. and Qiu, B.: Low-frequency variability of the North Pacific Ocean: The roles of boundary-and wind-driven baroclinic Rossby waves, J. Geophys. Res.-Oceans, 107, 13-1-13-10, 2002.

Haney, R. L., Hale, R. A., and Dietrich, D. E.: Offshore propagation of eddy kinetic energy in the California Current, J. Geophys. Res.-Oceans, 106, 11709-11717, 2001.

Heffner, D. M., Subrahmanyam, B., and Shriver, J. F.: Indian Ocean Rossby waves detected in HYCOM sea surface salinity, Geophys. Res. Lett., 35, doi:10.1029/2007GL032760, 2008.

Johns, W., Yao, F., Olson, D. B., Josey, S. A., Grist, J. P., and Smeed, D. A.: Character and dynamics of the red Sea and the Persian Gulf outflows, J. Geophys. Res.-Oceans, 105, 6387-6414, 2000.

Large, W. G., McWilliams, J. C., and Doney, S. C.: Oceanic vertical mixing: A review and a model with a nonlocal boundary layer parameterization, Rev. Geophys., 32, 363-403, 1994.

L'Hegaret, P., Lacour, L., Carton, X., Roullet, G., Baraille, R., and Correard, S.: A seasonal dipolar eddy near Ras Al Hamra (Sea of Oman), Ocean Dynam., 63, 633-659, 2013.
Matsuyama, M., Kitade, Y., Senjyu, T., Koike, Y., and Ishimaru, T.: Vertical structure of a current and density front in the Strait of Hormuz, Terrapub, Tokyo, C3, 23-34, 1998.

Morel, Y. and McWilliams, J.: Evolution of isolated interior vortices in the ocean, J. Phys. Oceanogr., 27, 727-748, 1997.

Pous, S., Lazure, P., and Carton, X.: A model of the general circulation in the Persian Gulf and in the Strait of Hormuz: Intraseasonal to interannual variability, Cont. Shelf Res., 94, 55-70, 2015.

Pous, S. P., Carton, X., and Lazure, P.: Hydrology and circulation in the Strait of Hormuz and the Gulf of Oman - Results from the GOGP99 Experiment: 1. Strait of Hormuz, J. Geophys. Res.Oceans, 109, 1978-2012, 2004a.

Pous, S. P., Carton, X., and Lazure, P.: Hydrology and circulation in the Strait of Hormuz and the Gulf of Oman - Results from the GOGP99 Experiment: 2. Gulf of Oman, J. Geophys. Res.Oceans, 109, 1978-2012, 2004b.

Rao, S. A., Behera, S. K., Masumoto, Y., and Yamagata, T.: Interannual subsurface variability in the tropical Indian Ocean with a special emphasis on the Indian Ocean dipole, Deep-Sea Res. Pt. II, 49, 1549-1572, 2002.

Roquet, F., Wunsch, C., and Madec, G.: On the patterns of wind power input to the ocean circulation, J. Phys. Oceanogr., 41, 2328-2342, 2011.

Schott, F. A. and McCreary Jr., J. P.: The monsoonal circulation of the Indian Ocean, Prog. Oceanogr., 51, 1-123, 2001.

Schott, F. A., Xie, S. P., and McCreary, J. P.: Indian Ocean circulation and climate variability, Rev. Geophys., 47, doi:10.1029/2007RG000245, 2009.

Senjyu, T., Ishimaru, T., Matsuyama, M., and Koike, Y.: High salinity lens from the Strait of Hormuz, in: Offshore Environment of the ROPME Sea Area after the War-Related Oil Spill, Terrapub, Tokyo, 35-49, 1998.

Shetye, S., Shenoi, S., Gouveia, A., Michael, G., Sundar, D., and Nampoothiri, G.: Wind-driven coastal upwelling along the western boundary of the Bay of Bengal during the southwest monsoon, Cont. Shelf Res., 11, 1397-1408, 1991.

Shi, W., Morrison, J. M., Bohm, E., and Manghanani, V.: The Oman upwelling zone during 1993, 1994 and 1995, Deep-Sea Res. Pt. II, 47, 1227-1247, 2000.

Smith, K. S.: The geography of linear baroclinic instability in Earth's oceans, J. Mar. Res., 65, 655-683, 2007.

Thoppil, P. G. and Hogan, P. J.: On the mechanisms of episodic salinity outflow events in the Strait of Hormuz, J. Phys. Oceanogr., 39, 1340-1360, 2009.

Vallis, G. K.: Atmospheric and oceanic fluid dynamics: fundamentals and large-scale circulation, Cambridge University Press, 2006.

Verron, J., Davies, P. A., and Dakin, J. M.: Quasigeostrophic flow past a cape in a homogeneous fluid, Fluid Dyn. Res., 7, doi:10.1016/0169-5983(91)90002-Z, 1991.

Vic, C., Roullet, G., Carton, X., and Capet, X.: Mesoscale dynamics in the Arabian Sea and a focus on the Great Whirl life cycle: A numerical investigation using ROMS, J. Geophys. Res.-Oceans, 119, 6422-6439, 2014.

Wang, Z., DiMarco, S. F., Jochens, A. E., and Ingles, S.: High salinity events in the northern Arabian Sea and Sea of Oman, DeepSea Res. Pt. I, 74, 14-24, 2013. 
Yao, F. and Johns, W. E.: A HYCOM modeling study of the Persian Gulf : 1. Model configurations and surface circulation, J. Geophys. Res.-Oceans, 115, C11017, doi:10.1029/2009JC005781, 2010a.
Yao, F. and Johns, W. E.: A HYCOM modeling study of the Persian Gulf : 2. Formation and export of Persian Gulf Water, J. Geophys. Res.-Oceans, 115, C11018, doi:10.1029/2009JC005788, $2010 \mathrm{~b}$. 